
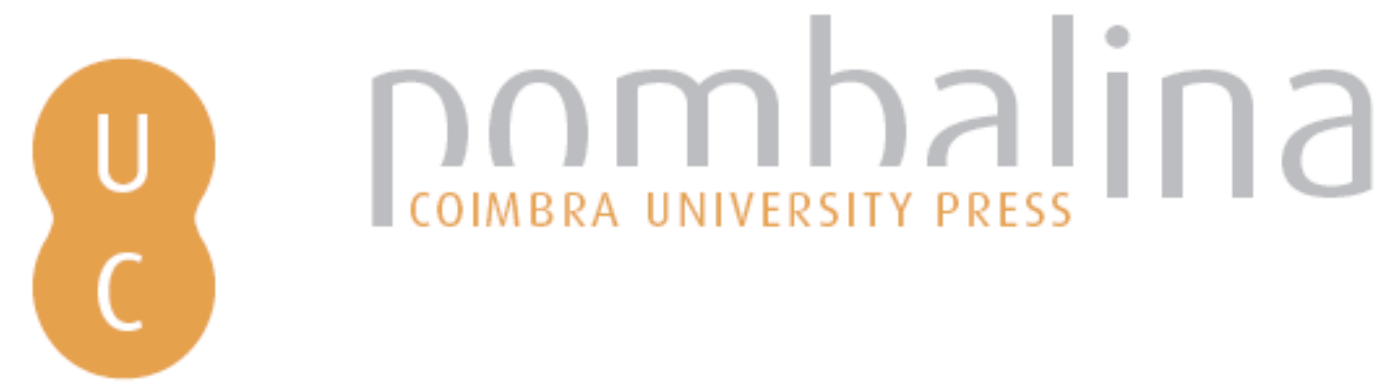

\title{
La dote feminina: posibilidades de incremento del consumo al comienzo del ciclo familiar: cultura material castellana comparada (1650-1850)
}

Autor(es): $\quad$ García Fernández, Máximo

Publicado por: Imprensa da Universidade de Coimbra

URL

persistente: URI:http://hdl.handle.net/10316.2/31583

DOI: $\quad$ DOI:http://dx.doi.org/10.14195/978-989-26-0201-1_5

Accessed : $\quad$ 26-Apr-2023 14:12:14

A navegação consulta e descarregamento dos títulos inseridos nas Bibliotecas Digitais UC Digitalis, UC Pombalina e UC Impactum, pressupõem a aceitação plena e sem reservas dos Termos e Condições de Uso destas Bibliotecas Digitais, disponíveis em https://digitalis.uc.pt/pt-pt/termos.

Conforme exposto nos referidos Termos e Condições de Uso, o descarregamento de títulos de acesso restrito requer uma licença válida de autorização devendo o utilizador aceder ao(s) documento(s) a partir de um endereço de IP da instituição detentora da supramencionada licença.

Ao utilizador é apenas permitido o descarregamento para uso pessoal, pelo que o emprego do(s) título(s) descarregado(s) para outro fim, designadamente comercial, carece de autorização do respetivo autor ou editor da obra.

Na medida em que todas as obras da UC Digitalis se encontram protegidas pelo Código do Direito de Autor e Direitos Conexos e demais legislação aplicável, toda a cópia, parcial ou total, deste documento, nos casos em que é legalmente admitida, deverá conter ou fazer-se acompanhar por este aviso.

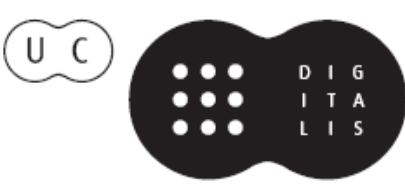


Isabel dos Guimarães Sá Máximo García Fernández (directores)

\section{PORTAS ADENTRO comer, vestir, habitar} (ss. XVI-XIX) 


\title{
LA DOTE FEMENINA: POSIBILIDADES DE INCREMENTO DEL CONSUMO AL COMIENZO DEL CICLO FAMILIAR. CULTURA MATERIAL CASTELLANA COMPARADA (1650-1850)
}

\author{
Máximo García FernándeZ \\ Departamento de Historia Moderna ${ }^{1}$ \\ Universidad de Valladolid (España)
}

Las cartas de pago de dote femeninas redactadas en la Castilla del Antiguo Régimen y hasta mediados del XIX ofrecen enormes posibilidades para comprender la relación existente entre cultura material y consumo popular y para acercarnos al conocimiento de la evolución histórica experimentada (muy diferente en cada sector socioprofesional según su riqueza patrimonial) por aquellas comunidades urbanas y rurales en función de la posesión de un conjunto de enseres cada vez más numeroso, variado, contrastado y funcional, imprescindible para que las nuevas familias pudiesen ir modificando, lentamente, sus pautas de sociabilidad y civilización hacia modelos más modernos y burgueses. A medida que se ampliaba el mercado, los recursos económicos aumentaban y los criterios de la moda, la apariencia pública y la notoriedad social también se convertían en claves inmateriales y materiales vinculadas estrechamente a la tenencia de una serie de vestidos y objetos suntuarios, nuevos, confortables o prácticos, se iría produciendo una progresiva reactivación de la demanda de tales bienes.

Apoyándonos en estos planteamientos metodológicos, se ofrecen ya algunos resultados iniciales basados en nuestras propias investigaciones documenta-

${ }^{1}$ Este trabajo se inscribe dentro del Proyecto de Investigación, financiado por la Junta de Castilla y León (referencia VA049A08), titulado Cultura material, consumo, moda e identidades sociales. Mujer, vestido y apariencia en Castilla y en León durante el Antiguo Régimen (siglos $X V I-X I X)$. 
les ${ }^{2}$. El objetivo final es su comparación con las conclusiones obtenidas por los estudios realizados para otras regiones españolas y portuguesas.

\section{CUESTIONES METODOLÓGICAS DOTALES RELEVANTES}

En las cartas de pago de dote femeninas protocolizadas ante notario público se fijaba el aporte económico dado por la mujer contrayente. El montante final (aunque próximo casi nunca coincidía con lo estipulado en las capitulaciones matrimoniales) sólo se conocía tras la tasación y el certificado de entrega correspondiente. Dadas sus implicaciones hereditarias posteriores, al ser de plena propiedad de la esposa («adelantos a cuenta de sus futuras legítimas hereditarias»), el marido únicamente declararía los objetos efectivamente recibidos, reconociendo efectivamente su existencia, lo que refrenda, sin olvidar posibles ocultaciones y estrategias interesadas, la validez de esta fuente documental.

$\mathrm{Al}$ ser el instante de mayor vitalidad consumista, a través de su estudio (más el análisis de los bienes de los inventarios postmortem cotejados por Madureira ${ }^{3}$, Yun $^{4}$, Levi $^{5}$, Roche $^{6}$, Schuurman $^{7}$, Ago $^{8}$, McKendrick $^{9}$, Shammas $^{10}$ o Weatherill ${ }^{11}$ )

${ }^{2}$ Como por ejemplo: M. García Fernández y B. Yun Casalilla, «Pautas de consumo, estilos de vida y cambio político en las ciudades castellanas a finales del Antiguo Régimen. Sobre algunas teorías del crecimiento económico desde la perspectiva de la demanda», en J. I. Fortea Pérez (ed.), Imágenes de la diversidad. El mundo urbano en la Corona de Castilla (s. XVII-XVIII), Santander, Universidad de Cantabria, 1997, pp. 245-282.

${ }^{3}$ Nuno L. Madureira, Lisboa. Luxo e distinção, 1750-1830, Lisboa, Fragmentos, 1990. Y, fundamentalmente: N. L. Madureira, Cidade: Espaço e Quotidiano (Lisboa 1740-1830), Lisboa, Livros Horizonte, 1992; donde ofrece nuestras mismas líneas metodológicas. Tres cortes (1740$50,1780-86$ y 1821-27) a intervalos de 25 años, para ver la evolución de la infraestructura cotidiana de cada generación. Estudio de inventarios post-mortem urbanos, comparados con los ambientes rurales. Análisis de todos los bienes de vestuario y mobiliario de casa. Muestra: 49, 152 y 127 inventarios. Palabras clave: 'nunca' (en menos del 5\% de los casos), 'raro' (5\%-25\%), 'frecuente' (25\%-60\%), 'domina' (60\%-90\%) y 'casi todos' (más del 90\%). Igual que en Valladolid, generando serios problemas interpretativos, las tasaciones lisboetas contienen listas de piezas pero casi nunca la habitación de la casa donde se ubicaban; ob. cit., pp. 291-298.

${ }^{4} \mathrm{~J}$. Torras e B. Yun (dir.), Consumo, condiciones de vida y comercialización. Cataluña y Castilla, siglos XVII-XIX, Valladolid, Consejería de Cultura de la Junta de Castilla y Léon, 1999. También: E. Llopis, J. Torras e B. Yun (ed.), El consumo en la España pre-industrial, número extraordinario de la Revista de Historia Económica, Madrid, 2003.

${ }^{5} \mathrm{G}$. Levi, «Comportements, ressources, procès: avant la 'revolution' de la consommation», en J. Revel (dir.), Jeux d'échelles. La micro-analyse à l'experience, París, Gallimard, 1996, pp. 185-207.

${ }^{6} \mathrm{D}$. Roche, La culture des apparences. Une histoire du vêtement. XVIIe-XVIIIe siècle, París, A. Fayard, 1989.

${ }^{7}$ A. Schuurman, L. Walsh (ed.), Material culture: consumption, life-style, standard of living, 1500-1900, Milán, Proceedings Eleventh International Economic History Congress, 1994; o Ad van der Woude y A. Schuurman (eds.), Probate inventories. A new source for the historical 
y el inventariado comercial de las tiendas, puede conocerse tanto la tipología y calidades del vestido y de los objetos domésticos en su evolución desde mediados del XVII hasta 1850, como las pautas de adquisición, consumo y disfrute de los nuevos productos y tejidos.

Con todo, estas cartas matrimoniales ofrecen un fuerte predominio de la transmisión sobre el consumo y la aparición de objetos novedosos. Muchos de sus bienes eran heredados: primaban los recibidos de los progenitores y no los comprados en esos momentos en el comercio. No obstante, durante el siglo XIX, progresivamente aumentaron los enseres nuevos y adquiridos expresamente para donarlos («regalos») a la nueva familia. Esta cuestión provoca que, en una misma fecha, el inventariado de los stocks de diversos negocios no siempre coincida con las telas y vestiduras del ajuar, defiendo estos últimos mucho mejor la estructura de la demanda de tejidos, ropajes y otros bienes de casa existente una generación antes. Así, de la comparación de las prendas dotales con las almacenadas en las tiendas textiles se deduce que el escaparate nupcial era más inmovilista y mucho menos sujeto a los cambios de las 'modas'. Por lo tanto, la validez de las dotes sólo debe ser valorada en el medio plazo.

Pero también ofrecen un 'consumo vicario'. Al cumplir realmente esa función, cuando las piezas que tasan aparecen por las mismas fechas en tiendas e inventarios postmortem, informan de que fueron, efectivamente, mecanismos de transmisión de pautas de consumo modernas y medios eficaces de introducción entre las capas populares, urbanas y también rurales, de cambios en el gusto y en las modas. Pese a su carácter simbólico, o precisamente por ello, y al revelar la instantánea de la etapa más consumista del ciclo vital familiar, muestran los engranajes típicos de difusión de la demanda de los bienes textiles ${ }^{12}$. Al ser numerosas y dada la variedad y riqueza de los datos que proporcionan, son una alternativa complementaria a otras posibles fuentes documentales históricas.

study of wealth, material culture and agricultural development, Wageningen, Afdeling Agrarische Geschiedenis, Landbouwuniversiteit, 1980.

${ }^{8}$ Renata Ago, Il gusto delle cose. Una storia degli oggetti nella Roma del Seicento, Roma, Donzelli, 2006.

${ }^{9}$ N. McKendrick, «Commercialization and the economy», en N. McKendrick, J. Brewer y J. H. H. Plumb, The birth of a consumer society. The commercialization of Eighteenth Century England, Bloomington, Indiana University Press, 1982.

${ }^{10} \mathrm{C}$. Shammas, The pre-industrial consumer in England and America, New York, Oxford University Press, 1990.

${ }^{11}$ L. Weatherill, Consumer behaviour and material culture in Britain, 1660-1760, Londres, Routledge, 1988.

12 J. Torras, M. Durán y L. Torra, «El ajuar de la novia. El consumo de tejidos en los contratos matrimoniales de una localidad catalana, 1600-1800», en J. Torras y B. Yun (dirs.), op. cit., pp. 61-69. En esa línea de perfeccionar las fuentes utilizadas, se revela de gran interés el estudio de los inventarios de las tiendas urbanas y de los mercaderes. 
Además, estos intercambios formaban parte del complejo sistema hereditario castellano. Su contenido patrimonial estaba vinculado a las estrategias sucesorias, a las que se unían otras familiares-matrimoniales. Así, aunque la posición económica particular determinara, lógicamente, el alcance de la verdadera trascendencia de la transmisión de bienes en aquellos momentos, estableciendo la composición concreta de cada ajuar nupcial, estas consideraciones influyeron mucho en la ausencia-presencia en las mismas de ciertos enseres, como casas, tierras, dinero, etc. En todo caso, también debemos preguntarnos si, efectivamente, el consumo de bienes duraderos se articulaba en función de la renta y los patrimonios.

Nosotros comparamos la tasación dotal urbana con la rural en su evolución temporal (a través de los cortes cronológicos 1650-60, 1700-10, 1750-60, 1790$1800,1830-35$ y 1850-60), diferenciando también las secuencias según tramos patrimoniales. La elección de Nava del Rey, Olmedo y Peñafiel se debe a la disparidad existente entre dichas poblaciones agrícolas, constatada a partir de sus respectivos consumos y basada en su diferente grado de relación con el mercado y los circuitos comerciales ${ }^{13}$.

Deben segregarse los volúmenes patrimoniales 0-1.000 reales, 1.000-2.000, 2.000-5.000, 5.000-10.000 y más de 10.000 en las zonas rurales, frente a los más elevados 0-5.000 reales, 5.000-10.000, 10.000-20.000, 20.000-50.000 y más de 50.000 de Valladolid, tras valorar la marcada disparidad dotal aportada en ambos espacios. Estos datos ofrecerían dos tipos de sociedades: el sesgo en Nava, Olmedo y Peñafiel las concentra en los estratos sociales más bajos, mientras que los mayores contrastes socio-económicos internos de la ciudad ofrecen un abanico más diferenciado, cuantitativa y cualitativamente. No obstante, para realizar las oportunas comparaciones geográficas entre las familias con patrimonios documentados mínimos, ver si se producen más o menos cambios por 'efecto emulación' en los ámbitos campesinos que en el mundo urbano dentro de los mismos sectores de renta o si la cantidad de tejidos y vestiduras portados era mayor o menor en cada área, finalmente omitimos las dotaciones vallisoletanas superiores a veinte mil reales (la máxima en Olmedo), agrupando las dotes en los tramos 0-2.000 reales, 2.000-5.000, 5.000-10.000 y 10.000-20.000. Así, puede estudiarse el consumo textil de aquella gran mayoría de la población castellana con rentas inferiores, considerando además la hipótesis de que la distribución del ingreso se mantuvo constante durante todo el periodo analizado, al entender que

${ }^{13}$ Las 475 cartas de pago de dote utilizadas (a las 225 de Valladolid se unen otras 250 de las zonas rurales circundantes) fueron muchas de las realizadas ante los escribanos de Valladolid durante los decenios señalados. Se analizan unas 80 por periodo, abarcando también un número parejo de dotaciones en cada tramo económico, con el fin de extraer pautas evolutivas generacionales cada cincuenta años. Todas ellas corresponden a mujeres solteras (descartándose los aportes de las viudas dada su diferente estructura y tipología) y con padres vivos en aquel momento. 
la tasación de aquellos ajuares era proporcional a la renta, y que ésta permaneció invariable ${ }^{14}$.

También decidimos otorgar igual protagonismo al número de objetos dotales que a su tasación monetaria (la valoración de los componentes del stock). El recuento de la abundancia de cada tipo de productos según categorías sociales y períodos es muy útil para conocer los cambios en la demanda a largo plazo (permite comparaciones con otras áreas, evitando los sesgos derivados de las técnicas de inventariar y tasar, y también de cara al estudio del subsector textil dentro del gasto doméstico, donde es imprescindible considerar su valor y naturaleza, así como las transformaciones de materiales y tejidos). Precisamente, el número y las características de las piezas que integraban el ajuar de cada novia (stocks, no flujos) respondían a unos usos sociales -no escritos pero bien establecidossobre lo que debían aportar las nuevas esposas al matrimonio en función del grupo de procedencia o al que pretendían integrarse: la rigidez inherente a este hábito ejemplar es una ventaja para aproximarse a las tendencias de los patrones de consumo y a sus mecanismos de difusión.

En cualquier caso, la cuestión del deflactor utilizado también es fundamental. La introducción y difusión de nuevas prendas textiles y tejidos pudo estar fuertemente relacionada con y arrastrada por la evolución del precio del trigo. Tomando como base el periodo 1790-1800, y hasta que contemos con un 'Índice de Precios de Productos Industriales' más riguroso, nuestra hipótesis gravita en que cualquier análisis de la variación monetaria dotal debe matizar mucho las cifras extremas referentes a 1650 y 1850 , con el fin de ofrecer tendencias más fidedignas. Por esta razón no priorizamos en este estudio (aunque se comenten y valoren algunos datos porcentuales ya contrastados) la cuestión fundamental de la evolución temporal de las tasaciones -en reales constantes- de los distintos segmentos textiles dotales.

${ }^{14}$ Por eso, dentro de la composición de la muestra en cada área y atendiendo a su construcción y dispersión, como la cuantía máxima de las dotes de Valladolid se situaba en 72.203 reales, $66.276,57.561$ y 219.292 reales en cada corte cronológico consecutivo, mientras que en Olmedo era de 12.562 reales, $11.996,19.964$ y 14.176 reales respectivamente (en Peñafiel eran aún más bajas: 5.597 reales, $11.000,6.345$ y 7.174 reales), hemos reducido coherentemente la muestra para comparar la evolución del consumo de textiles de las capas medias y bajas de ambas sociedades, donde, además, debería apreciarse mejor el proceso de imitación socio-cultural que también tratamos de poner aquí de relieve.

No se tienen en cuenta ahora ese $14 \%$ de las dotes vallisoletanas superiores, con el fin de comparar correctamente los sectores sociales mayoritarios -artesanado y campesinado, respectivamente- en ambos espacios dentro de los patrimonios más numerosos pero menos relevantes económicamente. Considerando que la dote refleja la estratificación económica reinante, no se cotejan el conjunto de las dos sociedades, sino los sectores vallisoletanos con niveles patrimoniales inferiores -hasta veinte mil reales- (un $80 \%$ de la población urbana), con los mismos tramos rurales (donde sí engloban al conjunto del mundo agrario). Así, pueden contrastarse las diferencias entre ambos espacios en función de 'niveles de ingreso' semejantes. 
Un último problema significativo se relaciona con la dudosa permanencia del rigor de la instantánea que proporcionan a partir de 1820. ¿El hábito de dotar se iba perdiendo o se alteraba la composición cualitativa de lo donado entonces? La legislación y la propia consideración de los bienes legados por vía femenina al matrimonio estaban evolucionando entonces. Hasta la propia terminología cambiaba, lo cual debe alertar también sobre el análisis de la cuantificación de la media ${ }^{15}$ de piezas por dote; de igual forma que debe matizarse la constante disminución de algunos de los parámetros numéricos analizados después de la década de los años treinta del XIX.

Aún con todos esos problemas, seguimos refrendando la validez global de la fuente utilizada para los estudios vinculados a la cultura material y al consumo de productos textiles ${ }^{16}$.

\section{LOS STOCKS DOTALES Y EL CONSUMO DOMÉSTICO EN VALLADOLID}

Además del montante global de los bienes aportados, interesa contrastar la composición del ajuar dotal, incidiendo de forma especial en el vestido (tablas $\mathrm{n}^{\circ}$ 1 y 2). En ese sentido y además de aumentar el número de piezas, la deflación monetaria muestra un progreso en la demanda de objetos de vestir y de casa, al multiplicarse ésta dos veces y media entre las fechas extremas de la muestra -de 3.000 reales se pasó a 7.500-, y tras crecer 1'7 veces -hacia 1850- en el tramo de capital diez-veinte mil reales ${ }^{17}$.

La pauta de esa tendencia la marcaba la conformación del vestuario, aunque las conclusiones deban aquilatarse con el análisis de la cantidad de piezas del guardarropa y de ropa blanca. La vestimenta pasó de constituir un tercio del ajuar a más del $45 \%$ en los cortes extremos, evolución prácticamente similar a la experimentada por la composición dotal de quienes recibieron de cinco a veinte mil reales (mientras, en el tramo inferior ascendió aún más, veinte puntos, pero desde porcentajes de partida muy diferentes). Son datos de stocks más que de sustitu-

${ }^{15}$ A efectos de la evolución del recuento de los efectos consumidos o de sus implicaciones psicológicas o de civilización, no tienen el mismo significado las «seis servilletas y la tabla de manteles»-siete piezas- llevadas por la vallisoletana Isabel Ramos en 1799, que el «juego de mantelería» -una única pieza- de María Domínguez cincuenta y tres años después; Archivo Histórico Provincial de Valladolid (AHPV), Sección Protocolos, Legajos 3928 y 4098.

${ }^{16}$ Véase: M. García, «Los bienes dotales en la ciudad de Valladolid, 1700-1850. El ajuar doméstico y la evolución del consumo y la demanda», en J. Torras y B. Yun (dirs.), ob. cit., pp. 133-137.

${ }^{17}$ Véanse: J. Amelang, «A note on marriage contracts as a source for the social history or early modern Barcelona», en Estudis històrics i documents dels arxius de protocols, VIII (1980), pp. 237-243; o Ll. Ferrer, «Fratelli al celibato, sorelle al matrimonio... Catalogna (sec. XVIIIXIX)», Quaderni Storici, Fratello/Sorella, vol. 83, 1993, pp. 527-554. 


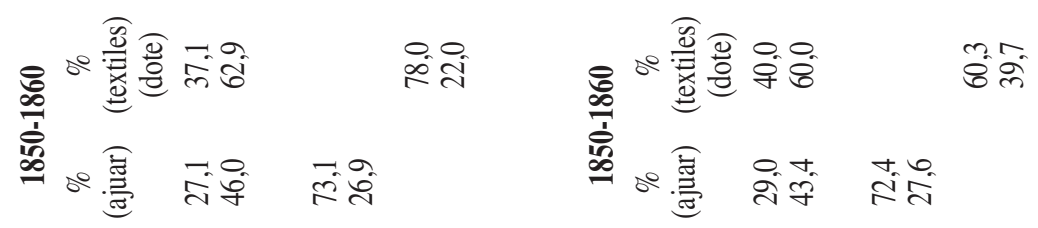

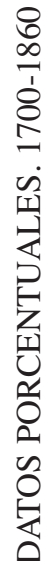

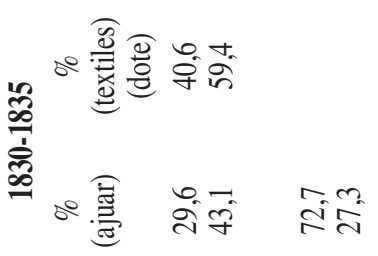

ํํㅇ

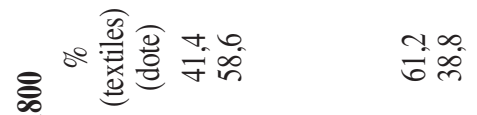

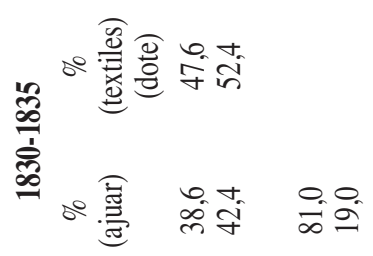

舟

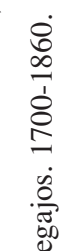

눈

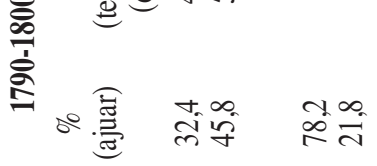

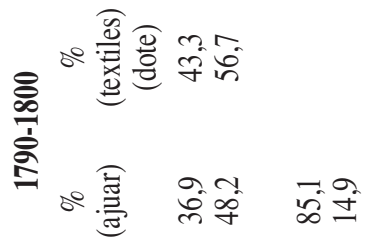

ํำ

\%

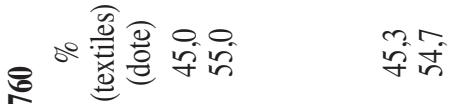

공

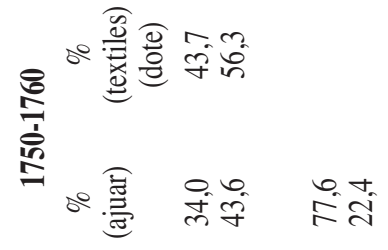

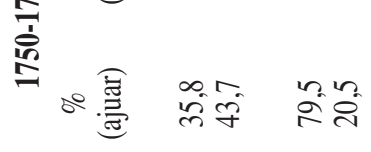

ฮี

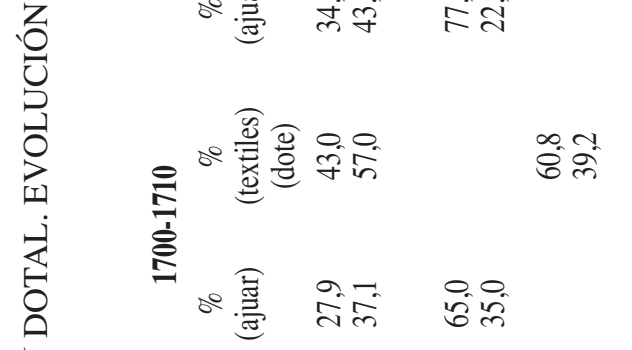

$\sum_{0}^{2}$

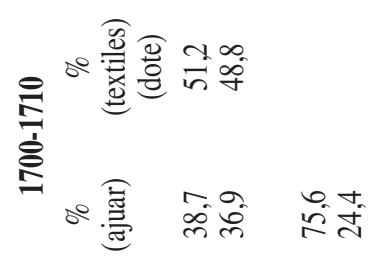

战㠻 


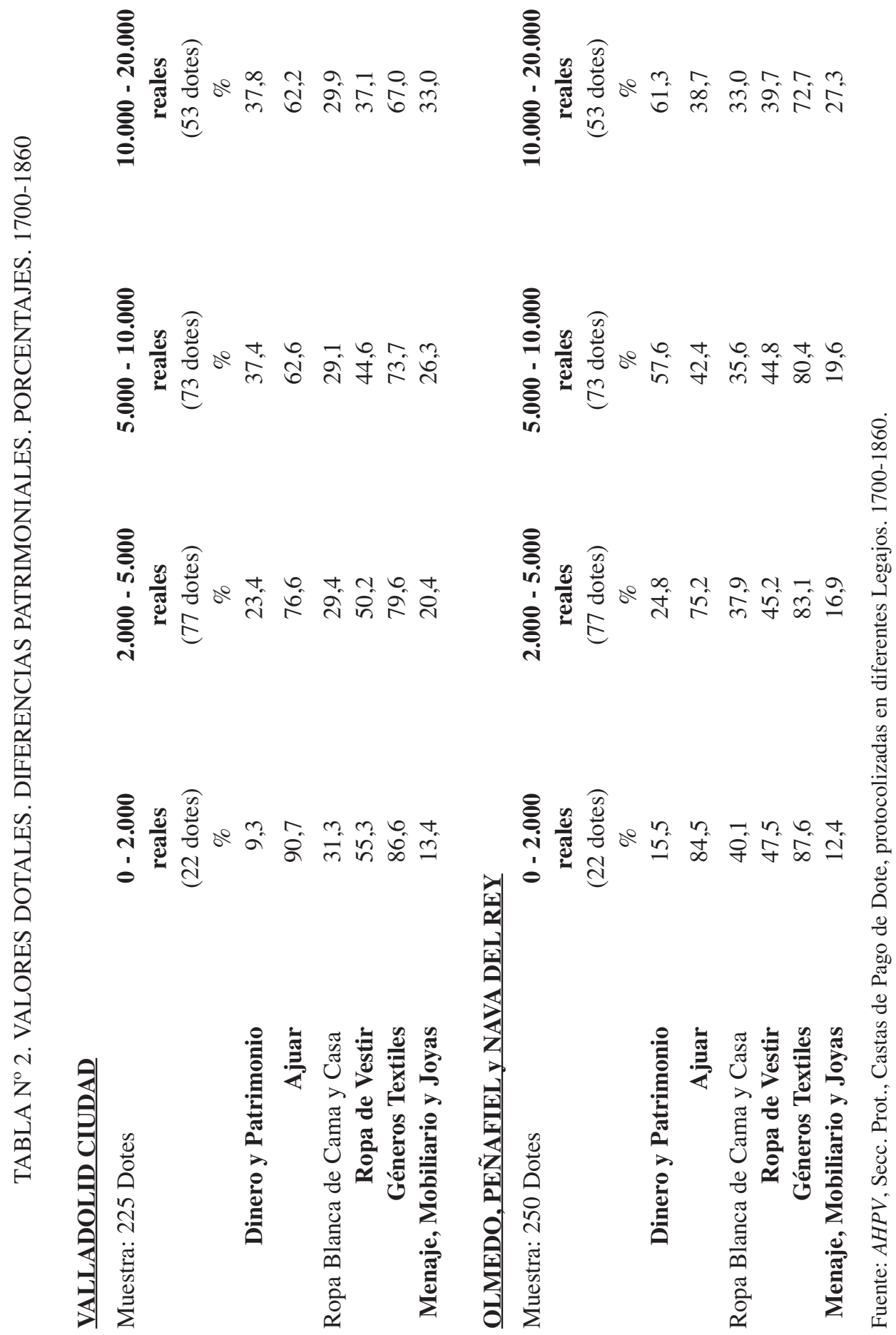


ción de productos, pero también un primer indicativo de las cantidades dedicadas a la adquisición de prendas y tejidos (más o menos novedosos) y de las tendencias de la demanda, de la transformación de los gustos, del cambio cualitativo y cuantitativo en la ropa interior y de la evolución de la moda externa femenina, provenientes desde el bloque superior de las dotes populares, donde resaltaron antes y con mayor (y lógica) nitidez los nuevos ropajes y telas, para calar posteriormente, por emulación, entre los sectores sociales inferiores y medianos en ascenso $^{18}$.

Por su parte, los elencos dotales apenas demuestran un gasto conspicuo y aparente, o un rasgo de refinamiento vinculado a un nivel de civilización considerable, en la 'ropa blanca' ${ }^{19}$. Salvando las diferentes calidades y el incremento de su número, no se aprecian variaciones porcentuales notables ni en la evolución cronológica ni individualizando la estratificación económica; es más, dentro de su escasa importancia en el ajuar, los 'paños de manos' y las mantelerías de mediados del siglo XVIII siempre eran superiores a los del XIX. Sólo para familias con dotes superiores a veinte mil reales era importante el adecentamiento de la vivienda y un buen servicio de su mesa (multiplicándose sólo entonces, y algunas con altas calidades y variedades). Más significativo es, sobre todo desde 1830, el aumento tanto de las dotaciones con 'tablas de manteles' y 'servilletas' como la media de esas piezas por dote.

La también estable presencia de la ropa de cama es mucho más significativa. Su tasación se había duplicado hacia 1850, aunque, salvo desde 1800 para el sector dotal intermedio y en el que tuvo siempre porcentajes muy elevados, cada vez representase menos dentro de los bienes duraderos. Jergones, mantas, colchones, colchas y la sabanería, normalmente presentes, con el paso del tiempo se convirtieron para ese grupo económico clave en signo de prosperidad, demostración y confort (tras la estela, siempre y cada vez más notoria, de los cuantiosos desembolsos -en el siglo XIX próximos a los cuatro y cinco mil reales- de quienes podían adquirir más en el mercado y transmitir a la generación siguiente). Es apreciable, además, la ligera tendencia porcentual alcista de estos géneros en todos los ajuares (incluso en los más modestos), máxime cuando esas cifras se complementan con la cantidad de piezas aportadas por las esposas: el número de

${ }^{18}$ Indicadores de la ampliación de la demanda en zapatería, textiles, mobiliario o menaje, de procedencia externa, según los estudios sobre moda, apariencia y vestuario femenino europeo de: C. M. Belfanti, «Le calze e maglia: moda e innovazione alle origini dell'industria della maglieria (secoli XVI-XVII)», Società e Storia, vol. 69, 1995, pp. 481-501; F. Orlando, Storia del costume femminile nel tardo barocco a Firenze, Milán, 1992; y D. Roche, ob. cit.

${ }^{19}$ Acertadas conclusiones sobre las nuevas fórmulas de percepción del cuerpo a partir del desarrollo de la higiene y del aseo textil, además de analizar el incremento de la sombrerería y estudiar los ajuares para conocer la diversidad cualitativa de las prendas burguesas, se encuentra en: R. Maruri, «Vestir el cuerpo, vestir la casa. El consumo de textiles en la burguesía mercantil de Santander, 1750-1850», en J. Torras y B. Yun (dirs.), ob. cit., pp. 159-180. 
sábanas, almohadones y cobertores se generalizaba primero para multiplicarse después.

Dentro de esos rasgos definitorios de 'cultura material' a partir de 'dotes tipo', la clave residía en los ropajes, la apariencia externa personal y lo mostrado hacia afuera, más que en lo privado, el vestido de la intimidad y el adecentamiento del hogar: las prendas para 'aparecer en público' eran capitales en el mundo urbano, frente al peso rural de 'vestir la cama'. 'Vestir el resto de la casa' carecía de relevancia. En todos los grupos populares se daba una gran importancia a los enseres constitutivos del ajuar textil. 'Vestir la persona' resultaba más perentorio y trascendente que decorar el interior de la casa ${ }^{20}$.

En suma, dentro del notable crecimiento experimentado por los ajuares dotales entre 1650 y 1850 , las tendencias de la demanda urbana partieron de la evolución expansiva y dinámica del consumo textil.

\section{CANTIDADES Y CALIDADES DEL AJUAR TEXTIL: CAMBIOS Y PER- MANENCIAS EN EL ATUENDO}

Dentro del mantenimiento generalizado de las pautas de demanda precedente, la tipología, calidad y cantidad de los enseres textiles y del mobiliario muestran mucho mejor los cambios más significativos. La gran cuestión estriba en concretar el valor evolutivo de la tenencia-consumo de ciertos productos.

La cronología de las piezas, y fundamentalmente de las más representativas, ofrece una amplia panorámica (aunque más próxima a la transmisión material que al mercado) de las necesidades femenino-domésticas respecto a ropas y tejidos, a la par que sobre la difusión numérica y social de otros enseres de consumo más dinámico e innovador, como prendas novedosas, armarios y escritorios, vasos de cristal, platos, cuberterías o la loza, y hasta claros rasgos de especificidad del uso de cada habitación ${ }^{21}$.

Las diferencias patrimoniales remarcaban una nítida clarificación entre objetos imprescindibles frente a los demostrativos de confort, lujo y rasgos modernos de civilización ${ }^{22}$. En ese sentido, la introducción de productos extranjeros en los ajuares femeninos de la Castilla interior sólo empezó a ser importante

${ }^{20}$ Véase: J. M ${ }^{\mathrm{a}}$ Díaz Hernández, La dote femenina en la sociedad jienense del siglo XVIII, Jaén, Instituto de Estudios Giennenses, 2004.

${ }^{21}$ Máxime para los elencos domésticos más cuantiosos y variados a partir de 1830; como la muy relevante dote de doña María Eusebia Puche, al casarse en 1833 con don Bruno Echevarri (AHPV, Secc. Prot., Leg. 12021, ff. 68-85).

22 Véase: P. Malamina, Il lusso dei contadini. Consumi e industrie nelle campagne toscane del Sei e Settecento, Bolonia, Il Mulino, 1990, pp. 135-163. Aunque analiza la zona rural toscana, merecen destacarse sus acertadas valoraciones. 
desde finales del siglo XVIII ${ }^{23}$. Entonces, y no únicamente ya entre los sectores con niveles de renta privilegiados, aunque fuesen portadas casi siempre por una minoría social relevante, además de las famosas indianas catalanas, las atractivas telas francesas, los sobrios paños ingleses y otras piezas de 'china' o 'manila' comenzaron a estar bastante presentes en las calles vallisoletanas típicas del paseo.

Además, de la diferenciación de vestidos, adornos del vestuario femenino y la ropa interior se desprenden cortes evolutivos muy significativos a partir de 1750 y apreciables mucho más nítidamente hacia 1830. Y comparando dichas prendas con el contenido de la tienda de productos textiles de Marcos Gómez en 1703 también se deducen interesantes conclusiones. Entre los abundantes géneros de su puesto comercial resaltaban los setenta vestidos de golilla en camelote, raso y bayeta; junto a los que se almacenaban 55 justacor -jubones-, en su mayor parte de raso de gredillo. Además, la mitad de las 23 basquiñas eran de camelote y de las 141 anguarinas sobresalían 52 de raso, 19 de camelote, 13 de tela de plata y 16 de tafetán doble; a lo que se unía una gran cantidad de ropillas, calzones y anguarinas (121 piezas): 37 de tafetán, 19 damascos y una quincena de tejido de raso. También destacaban: de la treintena de guardapiés 19 de raso y de los quince 'vestidos' ocho de camelote. A las anguarinas, con sus complementos, las seguían en número las basquiñas, jubones y delantales, más guardapiés y 'hábitos' femeninos; predominando como tejidos, conformando sus tres cuartas partes, el raso (35\%), el camelote (16\%), los tafetanes (13\%) y el damasco-damasquillo $(9 \%)$, seguidos de las bayetas (con un 5\%) ${ }^{24}$.

Por esas mismas fechas, las dotes informan de una clara supremacía de guardapiés y anguarinas, seguidas de basquiñas, almillas y mantos (la media de manteos y casacas en aquellos ajuares también era elevada; y sin desaparecer ni las numerosas 'ropas y ropillas' ni los jubones). La bayeta y la estameña de lana,

${ }^{23}$ Valladolid. Dotes Femeninas. Prendas confeccionadas con telas de procedencia extranjera (1650-1860); núm. y porcentajes.

Inglesas

Francesas

De India

De China o Manila

Otras (de Aroca, genéricas)

TOTAL Prendas

$\%$ sobre Total Prendas

$\%$ sobre Total Dotes

$$
\text { 1650-1760 }
$$

1

3

$3 \quad 14$

$14 \quad 26,9 \quad 30$

$\begin{array}{rr}23 \\ 30,8 & 3\end{array}$

$\begin{array}{lll}16 & 30,8 & 3\end{array}$

$\begin{array}{lll}6 & 11,5 & 8\end{array}$

52

$$
100
$$

1,1

14,3

28,3

\begin{tabular}{ccccc}
$\%$ & $1850-60$ & $\%$ & TOTAL & $\%$ \\
23,8 & 19 & 43,2 & 56 & 30,4 \\
35,7 & 5 & 11,4 & 52 & 28,3 \\
27,4 & 12 & 27,3 & 35 & 19,1 \\
3,6 & 6 & 13,6 & 25 & 13,5 \\
9,5 & 2 & 4,5 & 16 & 8,7 \\
100 & 44 & 100 & 184 & 100 \\
45,7 & & 23,9 & \multicolumn{2}{c}{100} \\
& 23,8 & \multicolumn{3}{c}{11,7}
\end{tabular}

pondían a su comercio textil.

Pueden compararse con la variedad de géneros que dos comerciantes de Valladolid asentaron -reuniendo unos 60.500 reales- para formar compañía de sedas y galones 85 años después; AHPV, Secc. Prot., Leg. 4074, sin fol., 1793. 
junto con los linos -holandas, de gusanillo, sedeña o estopa-, eran los tejidos predominantes. Mientras, otros géneros laneros, fundamentalmente la sempiterna, aún permanecían muy arraigados entre las típicas prendas castellanas de finales del XVII (junto a la felpa, el picote, el droguete o el pelo de camello, telas finas todas, lo mismo que las cotonías y muchos lienzos caseros o extranjeros).

Las prendas y tejidos aparecidos en ambas fuentes no difieren sustancialmente. Aún así, la presencia de guardapiés (la falda larga femenina más característica del siglo XVIII) es sensiblemente diferente y la proporción de bayetas y rasos está totalmente alterada. No existe, por lo tanto, una relación directa entre el comercio (y las posibilidades de acceso al mercado) y los stocks transmitidos de madres a hijas. Ya no se vendían bayetas, marcando su evolución desde finales del XVII, mientras la fuerte comercialización de los rasos definiría su crecimiento posterior en el estable escaparate inmovilizado, y mucho menos sujeto a los cambios de vestuarios y modas, de las dotes matrimoniales.

No obstante las inercias, la evolución cronológica de las vestiduras dotales indican la tendencia de las transformaciones de la confección y la cultura material a medio plazo. El periodo finisecular y 1830, fundamentalmente, centran el momento cumbre de ruptura. Las 'ropas y hábitos' (conjunto únicamente típico de esta época, promediando cinco por inventario) y los jubones componían el $45 \%$ de los ajuares de 1650; éstos, y los mantos, continuaban presentes al inicio del XVIII, cuando con almillas y anguarinas, y junto al inicio del desarrollo de guardapiés y basquiñas, constituían la base del vestuario femenino. 1750 fue momento culmen para guardapiés y casacas (basquiñas y delantales), y de las almillas, cotillas, briales y capotas, con el adorno de valonas, golas o vuelos y el arranque de la explosión de la guantería. Hacia 1800 se mantenían esas prendas cuando otras nuevas también se afirmaban ya como indumentaria modelo: repuntaban los jubones de calidad, mientras las omnipresentes basquiñas, delantales y guardapiés empezaban a competir con el enorme relieve iniciado por manteletas y zagalejos, mantillas y pañuelos.

Así, clarificando las innovaciones, de los 877 pañuelos, 367 corresponden al periodo de 1830 , y 74 mantillas de las 260 con que se adornaban los 179 vestidos y trajes de los 400 recontados. En 1850 el predominio correspondía (además de a las piezas características del corte precedente: 'vestidos y trajes', pañuelos y zagalejos) a los chales, manteos, manteletas, chambras y mantones ${ }^{25}$. Además, a partir de la década de los años treinta del XIX, se desarrolló de forma acelerada toda la ropa interior, apareciendo en la mayoría de las dotes en una

${ }^{25}$ Las prendas más características durante el siglo XVI eran el cuerpo y el verdugado, con las populares basquiñas, sayas y vaqueros. Mientras, en el XVIII, abundaban las basquiñas y mantillas, multiplicándose también, desde 1800, los corsés, enaguas, mangas, lazos y velos... junto a los zapatos y sombreros; véase: J. Laver, Breve historia del traje y la moda, Madrid, Cátedra, 1988. 
rápida multiplicación que alcanzaría la media de una decena de camisas (se recuentan más de 550) y calcetas, y también de 'mudas de ropa' y de pares de enaguas y medias en 1850, cuando cincuenta años antes, con una progresión ya apuntada desde 1750, se había iniciado el floreciente y veloz desarrollo del adorno y de un amplio complemento del vestuario (además del auge de la cintería y la cordonería, utilizadas en la remodelación de prendas antiguas para conferirlas aires novedosos): manual (conformado por la proliferación de bolsos, guantes y abanicos), de todo el surtido necesario para el tocado de cabeza (redecillas, velos, sombreros, sombrillas y peinetas) y del calzado (considerado ya no sólo como imprescindible, al contar cada esposa con más de tres y cuatro pares $)^{26}$.

Las piezas textiles aumentaban. La cantidad de guardapiés, basquiñas y jubones se incrementó hasta finales del XVIII, dando paso entonces a un fuerte desarrollo de mantones, mantillas y chambras, cuando la media de los diferentes vestidos y trajes más comunes se ampliaba. La multiplicación de los complementos del vestuario y la camisería todavía fue más significativa; y aún más la de la ropa interior.

Destacando ese cambio «del cuerpo cubierto al maniquí», no obstante, la tasación de prendas también refleja que las modas y la cultura material tenían unas limitaciones sociales y económicas muy marcadas: el acceso a un mayor consumo popular todavía era muy lento en el interior peninsular ${ }^{27}$.

Con todo, aquella relativa renovación del vestuario se acompañó por otra no menos importante, en cantidad y variedades, de la materia prima de confección, en la que destacó el paso trascendental del lino al algodón: evolución algodonera enmarcada en el mantenimiento del tradicional sector lanero (tabla $\mathrm{n}^{\circ} 3$ ).

$\mathrm{Al}$ agregar vestidos y ropa blanca, el tejido más abundante eran los lienzos, junto con la lana. Ésta siempre estuvo presente en los ajuares femeninos de todas las épocas, aunque proporcionalmente fuese disminuyendo progresivamente su importancia en el conjunto de los paños de cada quinquenio (en conjunto constituyó más del $60 \%, 45 \%$ y 33\%, hasta 1700 , en el siglo XVIII y con posterioridad). Por el contrario y a medida que los géneros de lino iban perdiendo su primacía (el 55\% se concentraban con anterioridad a 1710), el algodón (el 75\% aparecía después de 1830: un importantísimo $21 \%$ medio), más los hilos y sedas,

${ }^{26}$ Desde mediados del siglo XVIII, además del auge del casticismo y del 'majismo' (la 'maja' -con su falda de volantes, mantilla, peineta y abanico- y la 'manola'), aumentaron las modas importadas.

Por eso aumentaba la moda de los 'petimetres' afrancesados junto a los más sobrios, funcionales, prácticos, cómodos e higiénicos trajes ingleses (adoptados por la elite ilustrada desde la década de los años noventa del siglo XVIII); J. Laver, ob. cit., pp. 331-334.

${ }^{27} \mathrm{El}$ arraigo de las almonedas, los mercados de segunda mano y la frecuencia con que encajes, cintas o hilos aparecían entre los géneros de las tiendas de lencería demuestran que las prendas se readaptaban más que acelerarse la adquisición de nuevos productos: la polarización de la renta era desfavorable al incremento de una demanda masiva de textiles. 


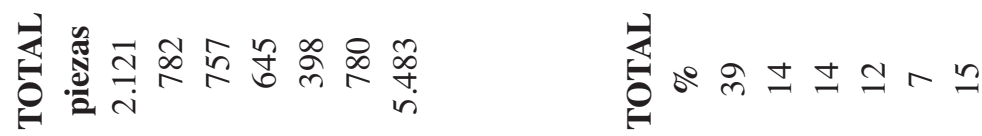

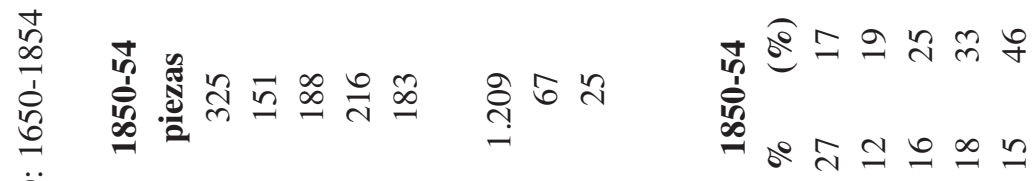

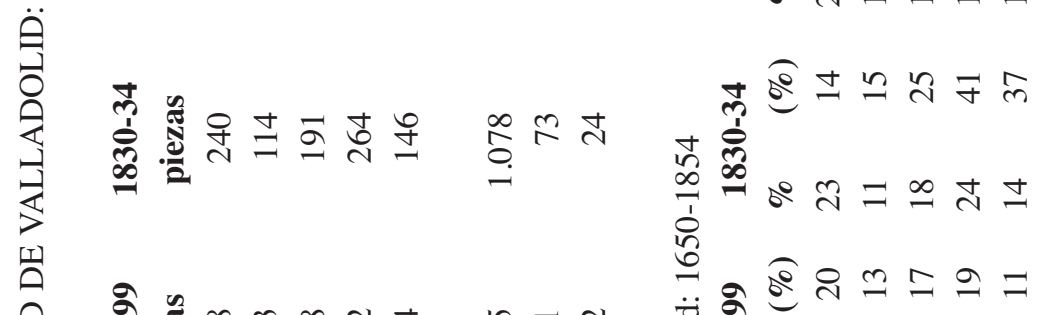

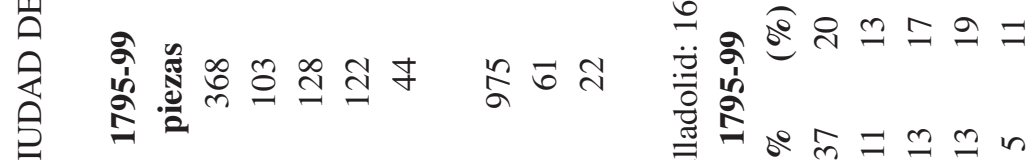

至

年

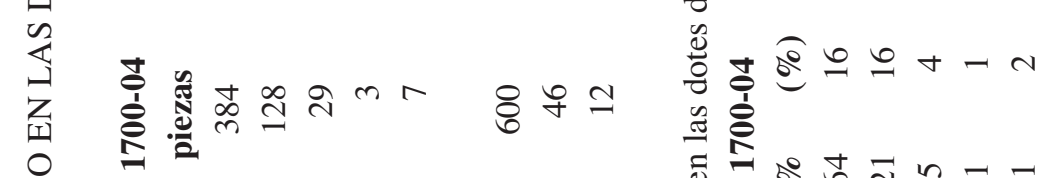

ฮำำ

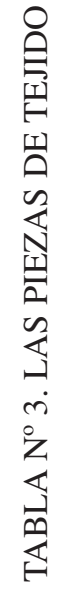

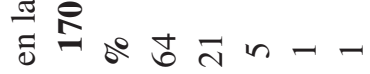

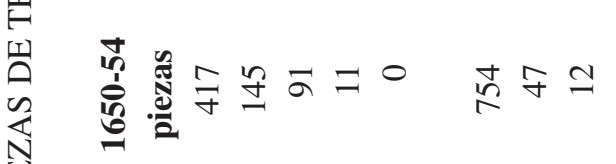

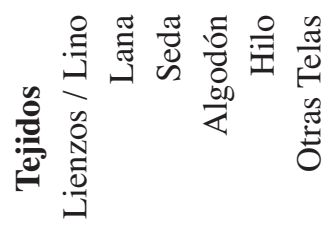

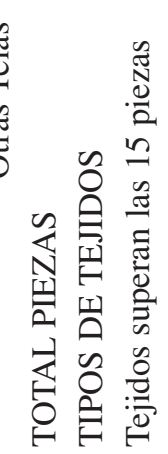

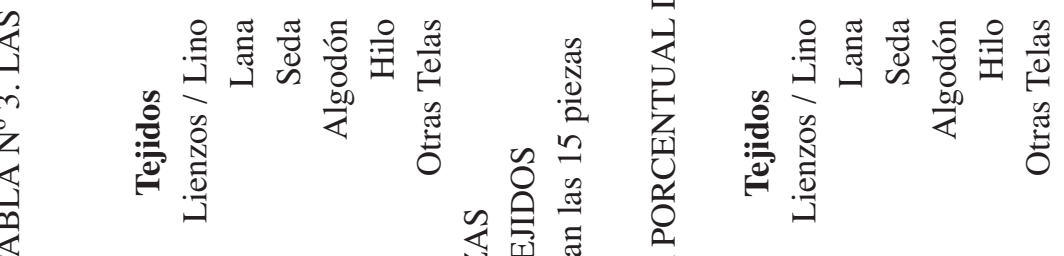


los reemplazaron. Otra cuestión diferente es su variedad interna y las distintas calidades.

Así, los lienzos 'caseros' o más tradicionales (portugueses, holandas, de Cambray o Morlés ${ }^{28}$ se sustituyeron por otros más modernos: primero por los finos de crea, trué, bocadillo y de media china, y después por los extrafinos extranjeros, cotanzas, mitanes y batistas. La clave radicó en el ocaso del lino gusanillo, sedeñas y estopas ante el empuje algodonero y de las sedas de calidad. Precisamente, en el algodón de la exclusividad del comercio de cotonías se pasó al auge de una floreciente y variada demanda de terlices y muselinas y, más adelante, de las típicas indianas, más los percales, chaconadas y franelas. Por su parte, y en el sector lanero, las estameñas, sempiternas, bayetas y lamparillas y otros paños bastos dejaron paso a la calidad de sus tejidos finos de confección: merino, cúbica, alepín, grana y carro de oro.

\section{MOBLAJE Y MENAJE DE CASA}

Este incremento cuantitativo y de diversificación formal textil también puede apreciarse en la especialización funcional del mobiliario doméstico, la ferretería, la loza y el ornato habitacional. Esta tendencia evolutiva apunta cambios cualitativos en la cultura material igualmente importantes para la Castilla urbana durante las primeras décadas del XIX. Imprescindibles siempre, sin embargo, formaban capítulos de importancia menor: muchas piezas (mesas, sillas o arcas) pero de escaso valor. A su vez, el adorno de la casa sólo crecía a medida que las familias podían permitirse tales dispendios.

Aún sin ofrecer tendencias nítidas, dentro del menaje y moblaje doméstico no era desdeñable que, precisamente en virtud del nacimiento de un nuevo hogar, el valor de cazuelas, sartenes, cuberterías y platos, superase al de mesas, sillas, baúles, cortinajes y cuadros. También es significativo que fuera en 1700 (con un $35 \%$ del ajuar urbano) cuando más caudales se emplearon en surtir la cocina y en la habitabilidad y acondicionamiento de la vivienda. Asimismo, en la evolución temporal únicamente pueden destacarse los dineros donados a las esposas con mayores dotes (hasta el 33\% de sus enseres). Por todo ello, el conjunto de estas pertenencias -donde los cambios fueron más cualitativos- presentaba escasa

${ }^{28}$ El desarrollo de las prendas de lencería, la mantelería y la ropa de cama resultó clave para la mejora de los espacios más íntimos. Las familias daban a las nuevas esposas (promedio) dos mantas y más colchones que jergones; las colchas fueron sustituyendo a los cobertores; y junto a las almohadas (hacia 1750 se contaban más de una decena por dote), sus almohadones y fundas aumentaron a partir de entonces. La sabanería (las 1.040 sábanas; 13 de media en 1850) constituyó siempre un sector capital. En cuanto a los textiles de mesa destaca como los más completos 'juegos de mantelería' iban desbancando a manteles, servilletas y paños de manos (en 1650 promediaban 13); el número de toallas para el aseo personal también creció. 
relevancia crematística para la gran mayoría de las numerosas dotaciones pobres de todos los tiempos.

Sólo en la ciudad, y únicamente en las dotaciones superiores, el 'adorno de casa' junto a 'lozas y cuberterías' comenzaron a ser importantes, mientras el 'moblaje doméstico' ya ascendía desde las situadas por encima de los cinco mil reales. Fue en las urbes donde la cantidad de piezas de mobiliario crecía hasta doblar en número a las existentes en la zona rural, aunque ese incremento del consumo de muebles únicamente se concretaba en las dotes de los grupos acomodados, y eso que el $40 \%$ de dichos enseres eran de pino, y de nogal el 15\% (de paja el 20\% de los asientos de las sillas en 1830). Además, seguían sobresaliendo los más tradicionales: arcas, bancos, camas, mesas y sillas.

El simbolismo de la tenencia de un menaje de mesa completo o de ciertos objetos de adorno y un mobiliario moderno y abundante diferenciaba culturalmente a sus propietarios. Así, sobre la base de baúles y bancos se irían superponiendo, en cantidad, calidad y variedad, los sitiales y sillas, primero, y después escritorios, rinconeras, sillones, poltronas, cómodas, tocadores, armarios roperos, mesitas de noche o sofás. De la misma manera que remarcaban distintas 'posiciones de civilización' la presencia de cuberterías o platos, y la adecuación de su número por persona; máxime cuando en ciertas viviendas había profusión de bandejas, cucharones, ensaladeras, salvillas, soperas y jarros, se producía la difusión de lozas, cristalerías y porcelanas chinas o se incorporaban al menaje usual, junto a las típicas chocolateras, las tacitas y cucharillas de café. La ausencia calefactora -salvo la permanencia de muchos braseros de cobre- o de las higiénicas palanganas incide en esa misma idea. Al igual que el disfrute de ornamentos 'sacralizados' (pilas de agua bendita, pinturas religiosas, rosarios, escapularios, relicarios, estampas...) junto a una variada tipología de útiles de plata labrada o joyería ${ }^{29}$.

En la concepción simbólica de lo doméstico aún no primaba el confort ni se exhibía la riqueza vía la acumulación de muebles, cortinas, alfombras, cristalerías o vidrios ${ }^{30}$. Con 'modernidad leve y tardía', se enriquecía y refinaba el menaje de cocina, aumentando el número y la calidad de platos y vasos (completos 'juegos y servicios de mesa'), las cuberterías y las originales salseras o ensaladeras. Y los hogares se poblaban de un moblaje innovador, como los escritorios ${ }^{31}$

${ }^{29}$ Véase: C. Hernández, Calles y casas en el Campo de Montiel. Hogares y espacio doméstico en las tierras de El Bonillo en el siglo XVIII, Albacete, Diputación Provincial de Albacete, 2007, pp. 351-400.

${ }^{30}$ R. Serrano, El fin del Antiguo Régimen (1808-1868). Cultura y vida cotidiana, Madrid, Síntesis, 2001, pp. 181-250.

${ }^{31}$ El entallador Juan Fernández hizo -en 1567- un vargueño tasado en 1.564 maravedíes «de dos tercios de hueco en largo, diez cajoncillos en tres carreras, cuatro en la primera, tres en la segunda y otros tres en la tercera, y el del medio grande, que quepa un pliego de papel doblado en hoja entera; y de hueco una tercia y dedo; a todo el cual ha de poner cerraduras, aldabones y bisagras; 
(y ya no vargueños, papeleras o escribanías), mientras se multiplicaban las cornucopias, cómodas, canapés, espejos y biombos, tanto en los salones como en las alcobas, rodeando las más o menos numerosas o ricas camas ${ }^{32}$. De ahí que la utilización del término cultura material para referirse a las mejoras introducidas en el ajuar, en el vestido personal y en los modales aún deba matizarse. Las viviendas estaban alhajadas y amuebladas pobremente, y sin reflejar una diferenciación funcional neta entre sus distintos espacios, ni tampoco organización interna según sexos o edades. Sólo desde 1830 se fue introduciendo otro modelo de casa y de edificio burgués. Aparecerían entonces nuevas habitaciones (el comedor, el vestíbulo, el 'cuarto de estar', el gabinete -o 'salita de confianza' femenina con su 'cuarto de costura'-, el despacho o, al lado de los orinales, el retrete o 'comunes ${ }^{33}$ ), separándose las áreas de sociabilidad de las dedicadas al uso privado. Así, mientras los salones ocupaban la parte delantera y noble, mostrando un mayor ornato y un rico y abundante mobiliario, alcobas y dormitorios interiores, limitando la promiscuidad, todavía no se decoraban con lujo. Entre los sectores acomodados también se desarrollaría, para difundirse después paulatinamente entre las clases populares, un mayor refinamiento del servicio de mesa (tras el aumento de las mantelerías y las servilletas individuales), mediante una amplia gama de objetos novedosos, una mejora sustancial de su calidad y constituyendo ya conjuntos unitarios: frente a los platos de barro y estaño, comenzarían a ser habituales las tazas, copas y jícaras de loza fina de Talavera, de Manises o de la Cartuja, el cristal y la porcelana china, de Sajonia o Limoges, generalizándose además los tenedores, lo que reforzó la presencia y uso del cuchillo, junto a los cucharones, los trinchantes o las cucharillas ${ }^{34}$.

y las delanteras de los cajones de nogal y así mismo lo demás de fuera»; AHPV, Secc. Prot., Leg. 364 (f. 459, 1567).

${ }^{32}$ Las habitaciones de doña María de Mendoza no eran la norma. Tenía diez camas ricas, sobre todo una, en la predominaba el carmesí: «dosel de dos piernas de tela de oro y tres de terciopelo carmesí, forrado todo de terciopelo azul, y el cielo del dosel con sus goteras y flocaduras de oro y seda; un cielo y dos cortinas de tela de oro y terciopelo, con sus alamares y franjas de oro y seda, forrado de anjeo; un cobertor de lo mismo con tres piernas de tela de oro y tres de terciopelo; dos cortinas de damasco con sus fajas y alamares de seda y oro; y dos rodapiés de terciopelo»; AHPV, Secc. Prot., Leg. 299 (f. 39, 1578).

${ }^{33}$ Aunque ya en 1581, en el jardín de la casa de don Rodrigo Manuel, se documente el primer excusado de Valladolid: «pedestal y orinal en una pieza, con las molduras de alabastro y su taza alrededor»; AHPV, Secc. Prot., Leg. 387, f. 18.

${ }^{34}$ No se resaltan aquí otras claves familiares dado que profundizamos en ellas en nuestro artículo «Evolución comparada de las pautas de consumo doméstico en el Sur de Europa (17001830)», Clio Nova Serie, vol. 18/19 (2008-09), pp. 367-396. 


\section{Y EN LISBOA... «CULTURA MATERIAL PARA LA DISTINCIÓN URBANA»}

«La casa de todo portugués es para él un asilo», procurando protección, amparo, abrigo y retiro: era un espacio sagrado. Su conocimiento proporciona claves sobre la evolución de las sensibilidades privadas, el culto por los objetos y espacios individualizados y la emergencia de una civilización del confort, dentro de una visión cosmopolita y moderna ${ }^{35}$. En esa idea, en 1782, Joao Rosado de Villa-lobos Vasconcelos editaba el manual de civilidad $O$ perfecto pedagogo na arte de educar a mocidade, tratando de instruir sobre buenas maneras, los comportamientos a mostrar en los paseos públicos y las actitudes más apropiadas dentro de casa (en la mesa, reglas para recibir visitas y convidar, etc.) y, pues sin la necesaria jerarquía doméstica el individuo no podía aprender las normas mundanas de la cultura burguesa. Los lugares concretos de cada objeto se estaban volviendo más selectivos, tomando una connotación negativa la no diferenciación funcional de cada apartamento. Así, debían fijarse y ajustarse los recintos a los nuevos hábitos sociales, cuando la especialización de unos arrastraba a los otros.

La evolución de los parámetros dotales vallisoletanos tiene una relativamente alta coincidencia con ese desarrollo burgués de la cultura material lisboeta de finales del Antiguo Régimen; también en cuanto al diferente grado de progreso social en su adecuación a la nueva mentalidad consumista.

Asegurando un 'territorio vital' frente al «igualitarismo de la pobreza que impedía el lujo de la diferencia», en la vivienda noble se distinguían guardarropas, gabinetes, camarines y salas de espera, junto a la cámara principal, íntima y ámbito privado. Por su parte, los hogares de artesanos y tenderos carecían de decoración interior, compartimentación individualizada o estancias privativas: presentaban un magma indiferenciado de espacios polivalentes, rusticidad sin codificar y una gran heterogeneidad funcional ${ }^{36}$. Allí aparecían los tamboretes (única forma de asiento en el $76 \%$ de aquellas casas, junto a los populares bancos) y las caixas (una media de 3,3 por residencia), incapaces de independizar zonas contiguas ni permitir a cada individuo la percepción de contar con un sitio fijo propio dentro del recinto familiar; tampoco los modernos muebles con cajones podían separar las ropas personales, cuando tradicionalmente solían apilarse en arcones, mezclando las prendas más lujosas con las de uso corriente. Sin definir apenas áreas de alojamiento y laborales, el 30\% de sus habitaciones, simples cuartos, no contaba con camas. Había pocos aposentos de dormir y las cocinas dedicadas exclusivamente a las tareas culinarias aún eran raras a finales del XVIII. «La especialización era un lujo».

\footnotetext{
${ }^{35}$ N. L. Madureira, Cidade...; 'Las casas', pp. 113-118 y 139.

${ }^{36}$ Ibidem, pp. 138-141.
} 
Para explicar la cultura y la vida privada debe valorarse la casa como otro índice de reputación y representación social -de civilización y privacidad-, la especialización de los espacios domésticos y del mobiliario y sus consecuencias para la evolución del consumo y los cambios en la organización de los ámbitos privados. De ahí, el interés por los ambientes especializados funcionalmente y la tendencia hacia la incorporación de la noción de intimidad en la convivencia cotidiana. Y de ahí la necesidad de valorar la escala de vanidades y gastos superfluos, el grado de comodidad, ostentación interior y confort, las perspectivas ajenas sobre mi residencia -iluminando zonas para las visitas-, el abundante y rico moblaje de los mercaderes a partir de $1750^{37}$-y de las clases medias desde 1820-, el sitio de cada cosa y el lugar apropiado de cada individuo, la percepción de 'universos personales', las estrategias higienistas combatiendo la insalubridad del hogar, la definición de límites frente a la promiscuidad, el progreso de la educación en etiqueta y protocolo o la divulgación popular de los Tratados de civilidad.

El mobiliario mostraba funcionalidad y utilidad cotidiana ${ }^{38}$. Los pleitos por la mera posesión de una silla denotan que para aquella sociedad eran un símbolo de jerarquía y protocolo ceremonial. Por agrupamiento y disposición, las series de muebles acentuaban la posición cabecera en cada lugar público, mientras que en el ámbito privado estructuraban compartimentos con funciones cada vez más específicas y 'nichos confortables'. Los conjuntos de media docena o doce piezas dentro de los salones definían confort, zonas donde conversas, jugar, beber o recibir visitas o espacios privados de bienestar dentro de la nueva sensibilidad que rodeaba aquella sociabilidad moderna y burguesa intramuros.

En cuanto al asiento, la silla con respaldo y/o brazos, denotando mayor riqueza, aún era poco frecuente a mediados del XVIII, cuando todavía predominaban los simples tamboretes bajos (aunque algunos tuviesen labrado moscovia, tapizado damasco, pata de cabra o pies de garra). Dispersos primero, hacia 1800 cada vez eran más frecuentes los conjuntos de seis o doce taburetes (homogéneos, y con funciones decorativas a la par que funcionales; confirmándose el hábito de encargarlas iguales a la ebanistería para determinadas salas donde recibir visitas o convivir mejor en la intimidad, en una división cada vez más especializada de las estancias). Se reducían los simples bancos de pino (de pared, colectivos, arrinconados ya a estancias secundarias y usados sólo para trabajos de cocina) o los moxos, mientras aparecía la solitaria y jerárquica poltrona, reservada para el jefe de familia, las de barbero, de niño o de mujer -como enseres específicos-, junto a otros asientos múltiples modernos: el canapé (de tres res-

${ }^{37}$ Ibidem, pp. 272 y ss. Ejemplo del inventario mueble, 'organización del espacio de la casa y su mobiliario', de un comerciante de Lisboa, en 1784: con un total de 194 piezas (en maderas -nobles-).

${ }^{38}$ Ibidem, 'Los muebles', pp. 151-155. 
paldos muchos) o el estilizado cabriolé francés (ofreciendo refinamiento, distinción y confort), en una progresiva sustitución del influjo Chippendalle inglés por el estilo francés Luis $\mathrm{XV}^{39}$.

Los 'Asientos' en las casas de Lisboa. 1740-1827 (328 inventarios); porcentajes

Sin Sillas-Cadeiras

Con alguna Silla-Cadeira

Poseían Conjuntos de Sillas-Cadeiras

$\begin{array}{cccc}\text { Inventarios } & 1740-50 & 1780-86 & 1821-27 \\ 118 & 63,3 \% & 50,7 \% & 10,3 \% \\ 53 & 8,1 \% & 23,0 \% & 7,8 \% \\ 157 & 28,6 \% & 26,3 \% & 81,9 \%\end{array}$

Por su parte, los más habituales y característicos muebles de guarda eran los bajos, cubiertos e idóneos para todo, y hasta con buena cerradura, arcones, cajones, baúles y arcas: definiendo «los ritmos lentos de la vida cotidiana, indiferentes a la mudanza, negación perfecta de la sociedad de consumo». Entrado el XIX las arcas fueron desapareciendo, mientras caixas y baúles aumentaban, y aparecían ya los modernos armarios. El mobiliario de apertura por tapa fue sustituido por los mejor organizados de cajoneras (la elegancia de las gavetas de contadores y cómodas constituyó la gran innovación ilustrada) y por el auge de los de puertas (armarios y guardarropas de dos cuerpos: piezas clave ya del moblaje popular parisino, sus cajones permitían que no se arrugasen los vestidos) o los mixtos (pues también fueron típicos del XVIII las papeleras y escritorios: derivados de las cómodas, pero con su secretaría de trabajo encima, se vincularon al mundo de la cultura escrita letrada, aunque, además y atravesando en diagonal las fronteras sociales, su amplia divulgación permitiese exteriorizar la religiosidad privada $)^{40}$.

Los 'Muebles de Guarda' en las casas de Lisboa. 1740-1827 (328 inventarios); porcentajes

Sin Cómodas

Con Cómodas

[Sólo tenían Arcas-Baúles

$\begin{array}{crcc}\text { Inventarios } & 1740-50 & 1780-86 & 1821-27 \\ 140 & 98,0 \% & 52,0 \% & 10,2 \% \\ 188 & 2,0 \% & 48,0 \% & 89,8 \% \\ 92 & 69,4 \% & 34,2 \% & 4,7 \%]\end{array}$

Y cada vez había más mesas, de todo tipo y tamaño, más especializadas y versátiles: de juego, de trabajo, tocadores, de té... grandes bufetes (frente a los ricos oratorios precedentes)... y mesillas de salón y de cabecera de cama (ya en un $6 \%$ de los hogares de finales del XVIII). Más todo el progreso del mobiliario experimentado en torno a la 'mesa del comedor' 41.

${ }^{39}$ Ibidem, 'Cantidades, cualidades y calidades de los Asientos', pp. 155-178.

${ }^{40}$ Ibidem, pp. 178-194. Las cómodas se introdujeron vía los deseos de un comerciante lisboeta con contactos internacionales y, por lo tanto, al margen del típico proceso cultural inglés de imitación nobiliaria arriba-abajo.

${ }^{41}$ Ibidem, pp. 194-208. 
Y proliferaron los guardalozas, cantoneiras, vitrinas y rinconeras, bien equipadas todas, con su faceta expositiva y para conservar, próximas a las mesas de comedor. Concentración funcional aquélla exclusiva para estancias espaciosas, de altos techos y apropiadas para recibir, «dentro de la nueva noción burguesa del patrimonio» y en relación con el incremento del consumo de cerámicas y lozas finas de Vista Alegre o importadas de India, China o Inglaterra. Al lado de un cada vez más amplio ajuar decorativo de pared ${ }^{42}$ : con cuadros (muchas imágenes del santoral), cortinas (en vez de tapices), espejos junto al 'tocador' para la toilete femenina (ornamentales, estratégicos, ostentosos y superfluos, marcando el «acceso del individuo a su propia imagen») y una creciente iluminación artificial interior.

Por su parte, en la urbana Lisboa todavía muchos dormían encima del duro suelo (en un 26\% de las casas hacia 1780). Aunque así fuese, todos poseían colchones, jergones y sábanas, armados sobre rudimentarias o más labradas tablas. Allí se instalarían durante la noche los hijos, reservándose para el matrimonio la a veces única cama útil. Transportables todas fácilmente, las había de barras, catres elevados sobre bancos de pino y camillas de lona, más los leitos ${ }^{43}$. Durante el XVIII, realmente, no sólo designaba al mueble, con las mejoras introducidas mediante cortinas y doseles de cuatro columnas, sino al conjunto de su soporte más la amplia y necesaria serie de sus accesorios textiles. Aún así, frente a la «promiscuidad poco higiénica del espacio nocturno» se iba abriendo paso el reposo encamado.

En suma, e igual que en Castilla, nacimiento de las ideas de libertad y ciudadanía. Una nueva sociabilidad con otras reglas, cuyo impacto sobre la demanda alteraba la relación psicológica y afectiva de individuos y objetos. Ruptura de fronteras entre los dominios público y particular, donde conversar, jugar o bailar cotidianamente, dentro y fuera ${ }^{44}$. Innovación y divulgación (¿rápida?), siempre dentro de las 'lógicas de la diferenciación jerárquica' y mezclando el buen gusto y lo puramente decorativo con la solución a las nuevas necesidades, y agregando fuertes dosis de prestigio a la propia utilidad práctica.

${ }^{42}$ Ibidem, pp. 216-232.

${ }^{43}$ Ibidem, pp. 208-215. La literatura higienista, pedagógica y moral del momento, dirigida a toda la población, propugnaba el descanso y la necesaria ventilación de la habitación. Así, en 1791, Francisco de Mello Franco escribía su Tratado de educaçao física dos meninos, al ser muy frecuente el colocar las camas en alcobas pequeñas y oscuras.

${ }^{44}$ Ibidem, pp. 249-254. 


\section{REFLEJOS DE LO CASTELLANO EN PORTUGAL... O DE LO PORTU- GUÉS EN CASTILLA ${ }^{45}$}

En ese clima de disparidades y similitudes en la evolución del consumo y la cultura material de la Castilla interior respecto al devenir lisboeta, resulta imprescindible puntualizar las experiencias comparativas legadas por diversos viajeros portugueses cuando apreciaban los contrastes (bastante alejados a veces de la realidad cotidiana y popular), criticando más lo nacional que ensalzando lo ajeno.

No pocos de aquellos trotamundos reflejaron sus vivencias cotidianas durante sus estancias en Valladolid -en general en la Meseta Norte- o en Madrid, para descubrir lo que de novedoso u opuesto advirtieron en las prácticas habituales foráneas ${ }^{46}$. Siempre comparando, aquellos lusos contrastaban lo más interesante para sus ojos: casi siempre lo mejor de un lado para desprestigiar lo propio, cuando no las diferencias claves para comprender, o al menos exculpar, las carencias populares de procedencia. Los problemas metodológicos en este sentido se relacionan con los sesgos inherentes a esas miradas extrañas, pero interesadas siempre, tanto como por la sucesión de conceptos estereotipados y frecuentes copias de clichés culturales que este género literario fue creando con el paso del tiempo. En todo caso, tras su lectura podemos apreciar hoy rasgos controvertidos y otros comunes sobre la cultura material de ambos países y sociedades peninsulares. Resaltaremos aquí más los contrastes, con algunas analogías.

Señalemos primero que cuando ya a finales del XVI se decía que «en las fiestas de mascaradas de caballeros de Valladolid una cuadrilla de librea venía 'a la hungaresca' y otra 'de portugueses' con sombreros de tafetán» ${ }^{47}$ se estaban estableciendo claras diferencias entre vestir a la española -a la moda filipina con su sobrio negro sobresaliente- o hacerlo con ropajes que identificaban a cada grupo humano con otra nación y otro modo de mostrarse y aparecer diferentes, y que chocaban. Por eso mismo, apenas doce años después contamos con la completa relación redactada por Tomé Pinheiro da Veiga durante o tras su estancia en

${ }^{45}$ De forma general, véanse: C. García-Romeral Pérez, Bio-bibliografía de viajeros por España y Portugal (siglos XV-XVI-XVII), Madrid, Ollero y Ramos, 2001 (de ese autor: Bio-bibliografía de viajeros por España y Portugal (Siglo XVIII), Madrid, Ollero y Ramos, 2000; o (recop.), Viajeros portugueses por España en el Siglo XIX, Madrid, Ollero y Ramos, 2001; A. Maczak, Viajes y viajeros en la Europa moderna, Barcelona, Omega, 1996; J. Majada Neila y J. Martín, Viajeros extranjeros en Salamanca (1300-1936), Salamanca, Centro de Estudios Salamantinos, 1988; o J. M ${ }^{a}$ Sanz García, Recuerdos portugueses en Madrid, Madrid, Instituto de Estudios Madrileños, 1992. También: Álvares da Silva, Memórias das verdadeiras cauzas porque o luxo tem sido nocivo aos portugueses, 1789.

${ }^{46}$ J. García Mercadal, Viajes de Extranjeros por España y Portugal (Desde los tiempos más remotos hasta comienzos del siglo XX), 6 tomos, Valladolid, Junta de Castilla Y Léon, 1999.

${ }^{47}$ J. García Mercadal, ob. cit., t. II. E. Cock (1592), La Jornada de Tarazona, pp. 453-602 (p. 580). 
la entonces Corte vallisoletana, quien constantemente se referiría a lo que le llamaba la atención por calidad, cantidad o contraste. En esas comparaciones reiteradas entre ambos espacios, culturas e identidades creemos apreciar cierto desprecio por lo propio y la mayor placidez lisboeta para caer en brazos de aquellos boatos y lujos festivos cortesanos castellanos ¿Ciertas todas sus interesadas apreciaciones? Tras el análisis de sus relatos pueden extraerse interesantes conclusiones, dado que, sin duda, éste del portugués Pinheiro constituye el ejemplo más notable conservado.

En constante comparación con su tierra natal, dejó irónica constancia de la supremacía castellana en cuanto al desarrollo de los lujos cortesanos y las posibilidades femeninas de acceso al mercado de todo tipo de géneros comerciales para satisfacer sus crecientes necesidades. Básicamente, sus ojos recayeron en lo más notorio. En los trajes, en los medios para su adquisición y en su calidad. Unas visiones siempre centradas en las mujeres vallisoletanas. Párpados centrados únicamente en aquella elite que salía de paseo o se exhibía en las numerosas fiestas celebradas en las riberas del Pisuerga y en la cercanía del poder regio durante aquellos breves años de 1603-1604. Por eso, entre otras citas memorables, atestiguaba el lustre de los ropajes («las verdugadas ennoblecen Valladolid», vistiendo igual que «la novia portuguesa: zagalejo exterior debajo de la basquiña y manto sobrepuesto $»^{48}$ ). Calidades atisbadas que sobresalían también por el contraste de lo cotidiano extranjero con hechos sobresalientes -bodas, lo más boyantes posibles- de su Portugal natal.

Y oteaba negocio. Oportunidades de compra por tanto, y armonía entre demanda, posibilidades de consumo y oferta. «Para la venta de las galas hay en Valladolid más y mejores tiendas que en otra parte ninguna del mundo, en las que se ofrecen cuantas clases de sedas y brocados son conocidos; la costumbre de mandar a las mujeres tomen fiado cuanto necesitan para sí sin dar cuenta a los maridos arruina a los señores; también son de grandísima comodidad los comercios en que se vende toda clase de vestidos, faldellines y basquiñas, hechos de todas especies y riqueza de guarniciones y randas» ${ }^{49}$. ¿No las había, y mejores, en Lisboa? Claro que si. Entre aquellas elites capitalinas la riqueza de los ropajes podía ser habitual, siempre que las arcas familiares pudiesen costearlo... y los maridos permitiesen su adquisición libérrima o abriesen dispendiosos sus faltriqueras.

La consecuencia: adorno y fiesta continua visible por las calles castellanas. «Con toda esta buhonería y chucherías salen adornadas en los días de fiesta, que son para ellas los trescientos sesenta y seis del año bisiesto, porque nunca pier-

${ }^{48}$ Ibidem, t. II. Bartolomé-Tomé Pinheiro da Veiga (1603), Fastiginia o Fastos Geniales, pp. 761-788 (p. 768). Véase también: Fastiginia. Vida cotidiana en la corte de Valladolid, Valladolid, Ambito, 1989.

${ }^{49}$ Ibidem, t. II. Pinheiro, Fastiginia, p. 772. 
den uno ni dejan cosa en el arca que no lleven sobre sí; su traje es notoriamente mejor y más lucido que el de nuestras mujeres...; andan rara vez de negro» ${ }^{50}$.

Junto a notoriedad, lucimiento y lujo externo. «Lo que gusta a las castellanas son galas, plumas y regalos: la libertad en que se crían hácelas aborrecer las estrecheces de la religión». «La riqueza de la mujer consiste en sus vestidos y cadenas; su Dios su gusto». «Sus faldellines son la gala de que más se precian: mozas y viejas los gastan con dos palmos de randas de oro, pues si tienen buenos bajos bien pueden ir vestidas como gusten». Consecuencias estéticas que ilustran las claves externas creadoras entonces de la moda, y hasta, advertía Pinheiro, entremezcladas con algunos principios morales rectores fundamentales, cuando, incluso, gastaban para sus lutos «tocas de dueña o moños con cresta, con lo cual parecen más lozanas que unas doncellas: lo que tienen en el corazón bien lo muestran en el traje» ${ }^{51}$.

Además, proseguía, incidiendo sobre las distintas maneras de unos y otros: «estos paisanos siempre tienden a andar al revés de otras naciones y poner la honra y cortesía no en el traje, sino en diferenciarse de los demás: en enero, sombrero de olla (de manera que anda a la cortesana quien más fuera de costumbre viste); manteos pequeñitos, luego circulares; de allí a un mes lechuguillas. En cuanto a las mujeres, ninguna usa hoy verdugados en Castilla; las damas empiezan a andar en cabello y otras vuelven ya a los periquitos. Yo mientras estuve allí nunca gasté manteos abiertos; ahora que me voy, tentome el diablo y compré cuatro, a fin de aparecer enrocado» ${ }^{52}$. Ropajes según las estaciones, a los cuales debían acostumbrarse si no querían desentonar socialmente, pero remarcando las distancias.

Casi trescientos años después, todavía Goodolphim insistiría: «en el Prado [madrileño] vimos muy elegantes a las mujeres con la graciosa mantilla (esas graciosas figuras como bandadas de golondrinas) con que sólo ellas se saben adornar; y ninguna otra maneja un abanico como la española; unas a otras toman el modelo de sus vestidos haciendo comentarios acerca de la modista ${ }^{53}$. Mantillas y abanicos las identificarían siempre mucho mejor que cualquier otro adjetivo estético más valioso.

En suma: «el ver aquí la riqueza y brutalidad de los vestidos no se concibe; lo mejor son las tiendas de aderezos de mujer, como cadenas, plumas y medias de seda, que son infinitas y no hay cosa que allí no se halle, vendiéndose la mercancía por manos de tenderas muy bien ataviadas» ${ }^{54}$. Un certero resumen éste

${ }^{50}$ Ibidem, t. II. Pinheiro, Fastiginia, p. 774. «No gastan verdugado sino con su gorguera; mantos ya no usan».

${ }^{51}$ Ibidem, t. II. Pinheiro, Fastiginia, pp. 775, 777, 783 y 787. Por su parte, los hombres: «sólo gastan capuz de duelo treinta días tras el fallecimiento y paño oscuro».

${ }^{52}$ Ibidem, t. II. Pinheiro, Fastiginia, p. 780.

${ }^{53}$ Ibidem, t. VI. Costa Goodolphim (1871), Visita a Madrid, pp. 339-359 (p. 356).

${ }^{54}$ Ibidem, t. II. Pinheiro, Fastiginia, p. 773. 
sobre lujos externos y abastecimiento comercial general que, sin embargo, las dotes no privilegiadas y los inventarios de la mayoría de las pobres tiendas abiertas apenas muestran, en la medida en que ofrecen dos instantáneas identitarias contrastadas económica y socialmente.

Respecto a las vajillas y el menaje de casa también pueden encontrarse interesantes referencias. Lo curioso es que mientras el interior de las viviendas casi siempre presentaba tintes negativos y las tasaciones dotales apenas eran relevantes, todos los comentarios sobre aquel utillaje doméstico fuesen siempre tan positivos. Significaban: «en todo lo relacionado con el moblaje son los castellanos verdaderos príncipes» o «los vidrios de Valladolid son cosa bellísima: de todas las hechuras y tamaños; cántaros, penados a manera de cantimploras, retortas de mil invenciones que en Lisboa no logran verse y barrillos con brincos al cuello; así como porcelanas y otras cosas de cerámica». «Se gastan mucho en Valladolid los búcaros de Estremoz; y otros de Palencia que en nada se diferencian de los nuestros en el color, y sí sólo en el olor que no es tan fragante; si cabe, más ligeros, perfectos y labrados» ${ }^{55}$. Calidad, variedad... e importación de Portugal, desde donde, y ya en el XVI, se constata el frecuente arribo a la Castilla interior (además de otras procedencias nacionales: Talavera de la Reina, Alba de Tormes, Toro, Toledo, Plasencia, Cantalapiedra, Portillo, Barcelona, Ampudia, Medina del Campo o zamoranos y hasta turquescos o 'vidrios de Venecia') de 'barros' y cántaros de Lisboa y búcaros -vasos de cerámica para beber agua fresca-, cazuelas de barro, frascos, fruteros, garrafas de porcelana y «estuches de mujer dorados» de Portugal, al lado del genérico colonial «de la India -de Indias- de Portugal». Comerciantes transfronterizos que también proporcionaron «cuchillos de aparador 'del portugués'» (junto a otros de Alemania, bohemios finos, hechura de Flandes, de media Francia, de Malinas o de Vergara) ${ }^{56}$.

Por el contrario, y respecto a lo íntimo y doméstico del común de los hogares, los extranjeros tenían la idea de que: «la casa sólo es para dormir; Madrid vive en las calles, en el café y en los teatros ${ }^{57}$. Además, en torno a los propios desplazamientos viajeros, aquellos personajes padecieron sobremanera la maldad de la hospedería nacional y, en general, el acondicionamiento de las viviendas, sentenciando: las ventas del camino de Lisboa a Sevilla «carecen de comodidades, como de costumbre suelen ofrecer los hoteles franceses; no tienen camas, ni colchones y es preciso llevarlo todo consigo; los posaderos son ladrones, y fuera de vestirse y adornarse para la apariencia exterior no saben nada

${ }^{55}$ Ibidem, t. II. Pinheiro, Fastiginia, p. 772.

«En Estremoz se hacen pucheros de barro; y en Montemayor sombreros»; Ibidem, t. IV. E. Silhouette (1729-30), Viaje de Francia, de España,..., pp. 573-651 (p. 643).

${ }^{56} A H P V$, Secc. Prot., diferentes legajos de los siglos XVI, XVII y XVIII.

${ }^{57}$ J. García Mercadal, ob. cit., t. VI. Goodolphim, Visita ..., p. 357. «Quien quiere charlar va a los cafés y a reír a los teatros»; «sorprendentes sus cafés: por su elegancia y por el extraordinario movimiento a todas horas todos los días». 
más ${ }^{58} \mathrm{o}$ 《el cuarto de las posadas zamoranas [igual que en el resto de España] servía a la vez de alcoba y recibidor; aunque fuese tan reducido, contenía una cama, las tablas para otra, una silla, la mesa y dos grandes cofres para la ropa y el resto de los tesoros familiares ${ }^{59}$. En suma, residencias incómodas, mal equipadas, carentes de servicios mínimos, pequeñas y sin clara distribución funcional de sus espacios.

En todo caso, y en relación de nuevo con el tema capital de las costumbres públicas y privadas, la apreciación de algunas otras cuestiones femeninas siguió siendo, siempre, fundamental, tanto en Castilla como en Portugal. Así, las vivencias de La Melonnière en sus visitas lusitanas: «si se obtiene el permiso para entrar en el cuarto de las señoras de Lisboa, se las encuentra sentadas en el suelo sobre una estera y los hombres hablando con ellas desde el extremo; sólo los frailes tienen derecho a estar sentados en sillas sobre esa estera ${ }^{60}$, certificaban que todavía durante el XVIII el espacio privativo y ambivalente de los estrados mujeriles aún definía unos ámbitos preventivos propios.

En contraposición, y por comparación contrastada con la Castilla rural, también resaltaban algunas otras bondades lisboetas. Las referencias a las modas cortesanas son amplias, tratando aquellos de identificar dónde anchura de calzas, golillas, largas faldas para ocultar el pie, 'zapatos, sombreros y vestidos a la francesa' o el 'típico guardainfante español' eran más abundantes o habían desaparecido para indicar modernidad o apariencia antigua. Lo mismo que algunas conductas extrañas para los culturalmente foráneos respecto a 'tapadas', etiquetas, 'posición cabecera' y 'mano derecha'. Algunas citas son significativas al respecto. «En Lisboa, los hombres llevan los altos de las calzas más anchos que en España; no usan golilla [inmóvil al colocarse sobre el cuello del jubón] y se sirven de sombreros y de zapatos a la francesa $»^{61}$. «En Lisboa la reina va a la española, con el guardainfante ${ }^{62}$. «El traje de las señoras es muy galante; van cubiertas con un manto o dominó de la cabeza hasta los pies, de manera que todas se parecen y son irreconocibles; sólo se descubren ante el monarca» ${ }^{63}$.

«En la corte, cuando el rey sale de palacio, va vestido a la francesa [de rayette o fine]». «Todas las portuguesas se escandalizaron, porque es indecente en una dama, según su costumbre, el enseñar de ese modo su pie, lo que hace que lleven sus faldas tan largas que no se les ven los pies». «Si queréis hacerlas

\footnotetext{
${ }^{58}$ Ibidem, t. III. J. Sobieski (1611), El reino de España, pp. 177-188 (p. 183).

${ }^{59}$ A. García Simón (ed.), Castilla y León según la visión de los viajeros extranjeros. Siglos XV-XIX, Salamanca, Junta de Castilla y Leon, 1999. Joseph Townsend (1786-87), p. 364.

${ }^{60} \mathrm{~J}$. García Mercadal, ob. cit., t. IV. La Melonnière (1720-26), Memorias Instructivas para un Viajero, pp. 657-698 (p. 686).

${ }^{61}$ Ibidem, t. III. Koenigsmark (1659), Viaje de Madrid a Lisboa, pp. 387-389 (p. 388).

${ }^{62}$ Ibidem, t. IV. Anónimo (1700), Viajes hechos en diversos tiempos en España..., pp. 444497 (p. 494).

${ }^{63}$ Ibudem, t. IV. Melonnière, Memorias..., p. 666.
} 
honor, a la moda portuguesa, con la que vayáis por la calle, es preciso llevarla por el lado de la acera, y hay que salir y entrar el primero siempre y en cualquier lugar» ${ }^{64}$.

Sin duda, muy distinta etiqueta social y vestuario al portado en Portugal por el común del vecindario: «el vestido campesino es aquí diferente: los hombres, con buen aspecto y más limpios, traje oscuro y sombrero; las mujeres un pañuelo en la cabeza, con una especie de manta blanca, sin medias ni zapatos y todas usan la falda, el corpiño y los mantones de una gruesa tela de Inglaterra de diferentes colores; en la ciudad mantón y falda de paño negro, lo que les da un aire totalmente oscurecido» ${ }^{65}$. No obstante, bastante parecido -más o menos decente, pulcro y aseado- al pobre repertorio y colorido del atuendo identificador y guardarropía típicos de las comarcas castellanas próximas. En Lugo «noté cambios en el traje femenino: llevan un sombrero extraordinario, que desciende por detrás hasta media espalda, y no llevan ni medias ni zapatos»; en Astorga podía reconocerse el singular porte de las maragatas («es verdaderamente original») y en El Bierzo «no había ni capa, ni sombrero, ni nada que recordase las costumbres de Andalucía o La Mancha; excepto la lengua (aunque con dialecto malo)» ${ }^{66}$.

Ante aquel paralelismo visual en el ropaje externo popular advertido por las miradas viajeras a ambos lados de la frontera no debe extrañar que todavía durante el XIX se vieran numerosos «arrieros ambulantes portugueses recorriendo la provincia de Salamanca traficando en lienzos ${ }^{67}$. Recuérdese que Aroca fue una reconocida ciudad lusa productora y exportadora de dichos tejidos, como muestra su constante aparición en la documentación notarial vallisoletana. Ya antes, el término descaminos hacía referencia a los buhoneros y comerciantes extranjeros que introducían sus mercancías en Castilla sin pagar en los puertos secos. A partir del inventario de uno de los alijos aprehendidos a uno de ellos se constata la entrada desde Portugal de «ámbar cuajado, botones blancos de cristal y otros de vidrio verde, brocas de zapatero y arracadas, botones [negros] y cadenillas de alquimia ${ }^{68}$. También, y desde el XVI, entre las vestimentas tasadas en los registros de las dotes urbanas y rurales aparecían ${ }^{69}$ : «aparejos de camisas y ropas», abanicos, «bolsas y bolsillos de los trajes colgados al cinto», cintas, colchas, listones de lana, «erizos y otros adornos para

${ }^{64}$ Ibidem, t. III. A. Jouvin (1672), El Viaje de España y Portugal, pp. 634-637.

${ }^{65}$ Ibidem, t. V. W. Dalrymple (1774), Viaje a España y a Portugal, pp. 165-236 (p. 215).

${ }^{66}$ Ibidem, t. V. Dalrymple, Viaje..., pp. 201-206.

${ }^{67}$ A. García Simón, ob. cit. George Borrow (1835-39), p. 209.

${ }^{68}$ A. Rojo Vega, El Siglo de Oro. Inventario de una época, Valladolid, Junta de Castilla y Léon, 1996, p. 171 (1573).

${ }^{69}$ Numerosas escrituras notariales protocolizadas avalan esa procedencia lusa (junto a los mismos géneros llegados de Flandes, Milán, Túnez, Holanda, Ruán o Francia); por ejemplo: $A H P V$, Secc. Prot., Legs. 855 (f. 415, 1599), 6712 (f. 416, 1572), 47 (f. 123, 1550), 144 (f. 1.023 , 1561), 299 (f. 39, 1578) o 327 (s.f., 1576). 
el tocado», franjas de oro y esteras y esterillas blancas de Portugal. Bastantes, en diversidad, cantidad y precio asequibles. Junto a las guarniciones de escribanía (o abalorios enriquecedores de vestidos o colgaduras) 'del portugués' o el hiladillo de colores (orla de seda estrecha, para hacer agujetas y cordones de abrochar) 'del $\mathrm{n}^{\mathrm{o}}$ doce de Portugal'. Además de: algodones y beatillas (para hacer tocadillos, tocados, toquillas, tocas, cofias, camisas, paños de manos, manteles o toallas) de Portugal, hilos portugueses $-\mathrm{y}$ de Calicud- (destinados a entorchadillos, garbines, tranzaderas o disciplinas), «hierba de la India de Portugal» o los populares lienzos caseros curados lusitanos (para hacer colchones, camisas, cernaderos, calcetas, paramentos, corpiños, jubones, cielos de cama, cuerpos, forros de zaragüelles, talegas, almohadas y sábanas; usados también como sacamuelas, en las curas o, con sus encajes, 'de cabeza o narices' $)^{70}$. En ese sentido, entre las labores femeninas que ya en 1547 «mostraban a las niñas a labrar de punto y de coser» sobresalían, junto a las de Ciudad Rodrigo, de red, de cadeneta, de cruces y hojas, de cinto, de nudillo, deshilados, escalerillas, labor menuda, manojillos, nudos de cerezo, larguitos, lomillos, matices o vainicas, los afamados «bordados portugueses» ${ }^{71}$.

Productos que no tenían parangón con los que se podían adquirir en las bien abastecidas lonjas de la propia capital portuaria portuguesa. En cuanto a su calidad, el francés Jouvín, ya loaba complacido en la segunda mitad del XVII las bondades lisboetas en cuanto a la enorme facilidad para consumir allí cualquier mercancía. «El que no ha visto Lisboa no ha visto cosa boa: puerto al que abordan todas las naciones; es un placer el ir a pasear por ese gran mercado, para ver allí multitud de bienes de todas clases... teniendo cada género un cuartel diferente, tanto que parece que se está en una ciudad con calles y tiendas bajo las avenidas porticadas, que hacen que esa plaza tenga más de un cuarto de legua». «Tiene hermosos paseos y una situación de lo más ventajosa... su gran río, que desemboca en el océano, está cubierto por un número infinito de barcos, que llegan de todas las partes del mundo» ${ }^{72}$. Sin duda, reproducía lo que setenta años antes describiese Pinheiro da Veiga para Valladolid. Lo que significa que las mercadurías arribaban, mucho más y antes por vía marítima, siempre y cuando la demanda privilegiada solicitase naranjas o cualquier otro género de alto valor añadido. Máxime en épocas de crisis, la gran cuestión radicaba en la distribución de la riqueza y en la capacidad adquisitiva (junto a la propia oferta comercial) de conjuntos sociales consumistas cada vez más amplios.

Aquellos contrastes hispano-lusos también se hacían patentes en los aspectos culturales y en las prácticas religiosas externas, aunque en ningún sentido fuesen tan diferentes sus mentalidades... ni sus hábitos consumistas populares.

\footnotetext{
${ }^{70}$ AHPV, Secc. Prot., Legs. 235 (f. 293, 1547) o 47 (f. 123, 1550).

${ }^{71}$ AHPV, Secc. Prot., Leg. 636 (f. 81, 1585).

72 J. García Mercadal, ob. cit., t. III. Jouvin, El Viaje..., pp. 634-637.
} 
Aún así, se necesitan reflexiones imparciales para valorar en su justa medida referencias del tenor: «franceses e ingleses no odian a los portugueses, con los que se alían para resistir al español, nación insoportable por el desprecio que hace a todo el mundo» ${ }^{73}$.

\section{REFLEXIONES FINALES DE CARAA UNAS NECESARIAS CONCLUSIONES}

En la Castilla de la segunda mitad del siglo XVIII bastantes escritos aludían a que «ni mi madre ni mi abuela usaron jamás de invenciones: unas sayas de estameña, una basquiña, anguarina de paño fino los días recios, una capa sobre la cabeza con su vuelta negra, un abanico redondo de papel; éstas eran sus galas; así vivieron muy honradamente, y no tú, que los días de fiesta pareces una condesa y tus hijas marquesicas, siendo así que no sois más que unas pobres labradoras; y sin considerar que causáis risa a las personas de meollo, pues, al fin, por más que la mona se vista de seda, mona se queda» ${ }^{74}$.

O que: «se había pegado furiosamente el aire de la gran moda: hacían la cortesía a la francesa y hablaban el español del mismo modo, afectando los francesismos y su retintín». «El contagio francés infeccionaba con mucha especialidad a las mujeres: como todas son naturalmente inclinadas a la novedad, encuentran mucha gracia en las voces afrancesadas, y no es creíble la ansia con que lo han adoptado; es la manía de la extravagancia: nuestras damas todo lo hacen a la francesa, afectando el aire francés en todos sus gestos». «Ni es devoción, penitencia, mortificación o modestia, sino profanidad, ventolera, escarnio y sacrilegio; no creo que lo hagan por burla, sino porque la natural delicadeza de su sexo no las permite usar de unos paños tan bastos, que las brumarían». Era la especie de la mala moda: «se visten así no más que por antojo e invención de su loca fantasía; usan de este vestido por pura vanidad, y no parece sino que se valen de él para ser más desenvueltas; por ahora, no me opongo a que las solteras procuren lícitamente agradar a los hombres y engalanarse, cada una según sus posibles». «Sus cuatro enemigos capitales: el demonio, el mundo, la carne y el deseo de parecer bien ${ }^{75}$.

En suma, invenciones, galas, modas -malas modas francesas-, novedades contagiosas, ventolera, extravagancia, delicadeza, fantasía, desenvoltura y deseos de 'parecer bien' a los hombres, relacionados con la inmodestia y vanidad femeninas, y con una significativa pérdida del concepto de la honra social.

\footnotetext{
${ }^{73}$ Ibidem, t. III. Jouvin, El Viaje..., pp. 579-666 (p. 629).

${ }^{74}$ Fray José de Isla, Historia del famoso predicador fray Gerundio de Campazas (1758-68), Madrid, Edit. Nacional, 1978, pp. 794-795.

${ }^{75}$ Ibidem, II, pp. 614, 626 y 780-791.
} 
Desde esta óptica de la dinámica mental de los procesos de demanda, los textos precedentes encierran algunas lecciones fundamentales. El hecho de que 'su abuela nunca pensase ni usase jamás' buenos tejidos, salvo las 'invenciones' propias de los días festivos, informa sobre la enorme contracción popular de la apariencia pública diaria: simplemente vestían lo indispensable para el decoro corporal. El campesinado, aunque tuviese 'posibles', debía vivir, y muy honradamente, sin otras demostraciones ni galas que quebrantasen la estamentalización vigente. Sobresalir y aparentar no difuminaba el origen vulgar: sólo provocaba la carcajada de los privilegiados, aunque aquellas exhibiciones atentasen directamente contra su propia posición cabecera. Así, la 'gran moda afrancesada' ni siquiera debía reservarse al ambiente cortesano: su difusión y extensión social no era una mera cuestión de consumo: violaba esencias mucho más profundas. Es más, el 'contagio francés' centraba la imposición de aquellas conductas extrañas entre las mujeres, añadiendo 'nuevas malas costumbres': la pérdida de las esencias patrias tanto como el incremento de las ansias femeninas por adoptar peligrosos hábitos no tradicionales por 'pura vanidad' y un simple 'deseo de parecer bien' no siempre acorde con sus respectivos rangos.

Más aún, el atuendo, entonces, en su exteriorización social y económica, podría ser escenario de la lucha política. Sólo así se entiende que en el Cádiz de 1810 hubiera quien reivindicase la vuelta al «vestir a la antigua» porque con ello «vendría el pensar a la antigua, y con el pensar el obrar...» ${ }^{76}$.

En todo caso, Giovanni Levi ha reiterado que «el consumo es un misterio», y que aún siendo el ingreso una variable determinante, también lo eran la explicación psicológica y el vínculo del 'proyecto del ciclo vital y la edad' con la evolución de la demanda y la organización de la política del consumo familiar ${ }^{77}$.

La atención de las necesidades de cada nuevo hogar marcaba la estructura de la dote. No obstante y aunque siempre la apariencia externa fuese una de las claves de la diferenciación social, a medida que se aproximaba una época más liberal y burguesa otras consideraciones relacionadas con las modas o el lujo y el confort cotidiano se fueron acentuando, primero y de forma más acelerada en los centros urbanos. Por ello, además de los enseres imprescindibles, desde mediados del XVIII, otras muchas prendas y una cada vez mayor diversidad y cantidad de objetos se agregaron al ajuar, para cubrir ya no sólo las exigencias familiares básicas sino también un más amplio y variado lucimiento personal, a la par que unas mejores condiciones de habitabilidad y comodidad corporal, doméstica y pública, en el interior de las viviendas ${ }^{78}$.

${ }^{76}$ B. Pérez Galdós, Cádiz. Episodios Nacionales, Madrid, desde 1872 (Alianza, Madrid, 1976), pp. 35-39.

${ }_{77}$ G. Levi, Il costume e la moda nella società italiana, Turín, Einaudi, 1978.

${ }^{78}$ Véanse: V. Barbagli (ed.), Domanda e consumi: livelli e strutture (nei secoli XIII-XVIII), Florencia, Leo S. Olschki, 1978; G. Friz, Consumi, tenore di vita e prezzi a Roma dal 1770 al 1900, Roma, Archivio Economico dell'Unificazione Italiana, 1980; M. Baulant, A. J. Schuurman y P. Servais (eds.), Inventaires après-dècés et ventes de meubles. Apports à une histoire de la vie 
Razones por las que se pretende seguir profundizando en esta línea de investigación dotal.

La tenencia de bienes duraderos se articulaba en función del patrimonio y la renta. Las haciendas más reducidas presentaban unos porcentajes en textiles, adorno de casa, mobiliario y menaje de cocina muy elevados (superiores a las tres cuartas partes del equipaje dotal), mientras que en las dotes de los grupos acaudalados rurales, aunque fuesen notables las cantidades invertidas en vestir la casa y el cuerpo, con más objetos y diversificados, dada su mayor velocidad de renovación del ajuar (y pese a ser datos de stock más que referentes a la sustitución de productos), se concentraban en joyas, dinero en efectivo, bienes inmuebles y raíces, oficios públicos y los géneros de sus mercadurías. Así, la inversión-demanda domiciliaria y de vestuario tendía hacia valores mínimos al incrementarse los caudales. Por tanto, y aunque el consumo, tanto el más público y externo de la indumentaria como el doméstico, deba relacionar el ingreso con los conceptos de mentalidad, nivel cultural o el deseo de demostración de la posición social, puede apreciarse una clara diferenciación en la composición de la dote en función de la gradación de la riqueza: la disparidad era muy notable entre el $91 \%$ y el $39 \%$ destinados respectivamente por las más pobres y las que superan los diez mil reales a satisfacer las necesidades de vestido, cama y cocina-casa.

Al concentrarse las donaciones en el tiempo de la boda, la estructura habitual del consumo dotal en sus distintos niveles económicos presentaba fisonomías muy diferentes. La fortuna, formación y nivel cultural de la clase media de consumidores determinarían una propensión a la adquisición de productos mucho mayor que en los extremos de la base y la cúspide social. Empero, los bajos índices de inversión dedicada al ajuar doméstico entre los de mayores ingresos sólo implican que su peso relativo era reducido respecto al volumen total de los bienes aportados, y nunca inferior al de los grupos con menores recursos. La calidad de los enseres también precisa esas tendencias de la demanda, pues (sin definir el gasto real) se aprecia con nitidez el contraste de la importancia de los tejidos y la hacienda mueble frente al peso del dinero o los bienes raíces e inmuebles en función de la cuantía y gradación de las dotes ${ }^{79}$. Es evidente,

économique et quotidienne. XIV-XIX siècle, Lovaina, Academia, 1988; L. Fontaine, Histoire du colportage en Europe (XVe-XIXe siècle), París, Albin Michel, 1993; o M. S. Mazzi, «Gli inventari dei beni. Storia di oggetti e storia di uomini», Società e Storia (1980), pp. 203-214.

También: C. Paolini, I luoghi del cibo. Cucine, tinelli e sale da banchetto nella casa florentina tra XV e XVII secolo, Florencia, Polistampa, 2004; B. Blasco Esquivias, La casa: Evolución del espacio doméstico en España, Madrid, El Viso, 2006; y C. Paolini, I luoghi dell'intimità. La camera da letto nella casa florentina del Rinascimento, Florencia, Polistampa, 2004.

${ }^{79}$ Dentro de la teoría de la 'revolución industriosa' defendida por De Vries (J. Brewer y R. Porter (eds.), Comsumption and the world of goods, Londres, Routledge, 1993, pp. 90-130), la progresiva sustitución de los bienes de producción casera por otros adquiridos-comprados es otro claro reflejo del incremento de los vínculos de las economías familiares (con dotes superiores) con el mercado. 
por tanto, que aquellas adquisiciones dependían, en volumen y composición, del reparto de la riqueza ${ }^{80}$.

Así, pese a los problemas metodológicos e interpretativos, las dotes femeninas ofrecen un fuerte predominio de la transmisión sobre la aparición de nuevos productos: definen mejor la estructura del uso de tejidos, prendas y enseres de casa de la generación precedente que los donaba. Dibujando pautas continuistas, sin embargo, desde finales del XVIII reflejaban también cambios cualitativos sustanciales en los hábitos de vida, la cultura material y la demanda familiar doméstica $^{81}$. Así, el vestuario externo, el consumo textil y la demanda de confort en el interior de los hogares vallisoletanos pueden compararse con el devenir experimentado en los principales epicentros de civilización urbanos occidentales.

En definitiva, tanto por las cantidades del ajuar textil como por la composición de los tejidos nunca antes del primer cuarto del XIX se produciría un significativo momento de ruptura respecto al atuendo individual ${ }^{82}$. Sólo entonces proliferarían las Arcas de Noé, como el título favorito para algunas de aquellas primeras tiendas castellanas en las que se vendía y podía encontrarse de todo. ¿La evolución mental y económica urbana peninsular se adecuaba al devenir de la Europa occidental, o todas las transformaciones en la demanda y la cultura material llegaron con retraso, muy limitadas socialmente y con numerosos aspectos fluctuantes que mostraban más postulados tradicionales que modernidad europeizante? En todo caso, ¿el modelo español estuvo ligado al incremento del consumo nobiliario, siguiendo las pautas inglesas y romanas, siguió las versallescas y parisinas o cabría compararlas más claramente con el desarrollo burgués lisboeta?; ¿los avances se produjeron exclusivamente en el mundo cortesano, urbano y privilegiado, o se extendieron con ritmo constante y acelerado también 'trikle up'?

Los sectores sociales más pujantes de los países occidentales propugnaban nuevas demandas y notables cambios en sus estilos de vida: avanzaban hacia una civilización más moderna. La evolución de la cultura material y las transformaciones en los hábitos de consumo doméstico de la Castilla interior también apuntaban en esa dirección, aunque las contradicciones fuesen aquí mucho más notorias, los implicados en tal proceso poco numerosos, sus niveles de vida apenas mejorasen, las inercias, frenos y tradiciones se mantuviesen durante más tiempo y los límites a las modas y al consumismo popular fuesen muy evidentes.

Cambios y permanencias.

${ }^{80}$ I. A. Baixauli Juan, Casar-se a l'antic règim. Dona i familia a la València del segle XVII, Valencia, Universidad de Valencia, 2003, pp. 25-36.

${ }^{81}$ P. Saavedra y H. Sobrado, El siglo de las Luces. Cultura y vida cotidiana, Madrid, Síntesis, 2004, pp. 284-299.

82 Véanse: R. M ${ }^{a}$ Dávila Corona y M. García Fernández, «Vestirse y vestir la casa. El consumo de productos textiles en Valladolid (1700-1860)», Obradoiro de Historia Moderna, vol. 14, 2005, pp. 141-174; o M. García Fernández y R. Ma Dávila Corona, «El consumo de productos textiles en Valladolid, 1750-1850», Investigaciones Históricas, n. . 21, 2001, pp. 133-180. 